\title{
Capturing and holding attention: The impact of emotional words in rapid serial visual presentation
}

\author{
Karen J. Mathewson, Karen M. Arnell, and Craig A. Mansfield \\ Brock University, St. Catharines, Ontario, Canada
}

\begin{abstract}
When two masked, to-be-attended targets are presented within approximately $500 \mathrm{msec}$ of each other, accurate report of the second target (T2) suffers more than when targets are presented farther apart in time-an attentional blink $(\mathrm{AB})$. In the present study, the $\mathrm{AB}$ was found to be larger when taboo words were presented as a first target (T1), as compared with the $\mathrm{AB}$ found when emotionally neutral, negative, or positive words were presented as T1, suggesting that taboo words received preferential attentional processing. Comparable results were also obtained when taboo words were presented as to-be-ignored distractors in single-target rapid serial visual presentation (RSVP). Arousal, but not valence, ratings of the emotional words predicted accuracy on subsequent targets in both dual- and single-task RSVP. Recognition memory for taboo words accounted fully for the negative relationships between arousal ratings and accuracy on subsequent targets, suggesting that arousal-triggered changes in attentional allocation influenced encoding of taboo words at the time they were encountered.
\end{abstract}

In a typical rapid serial visual presentation (RSVP) paradigm, stimuli are presented rapidly (approximately $10 / \mathrm{sec}$ ) one at a time in the same central location. Participants are usually able to detect or identify a specified single target with a high degree of accuracy (Raymond, Shapiro, \& Arnell, 1992). However, they have difficulty reporting the second of two targets if the second target (T2) is presented within about $500 \mathrm{msec}$ of the first target (T1) - an effect known as the attentional blink (AB; Broadbent \& Broadbent, 1987; Raymond et al., 1992). No $\mathrm{AB}$ is observed if participants are instructed to ignore $\mathrm{T} 1$ and report only T2 (Raymond et al., 1992), or if the targets are presented farther apart in time.

According to prominent two-stage bottleneck models of the AB (Chun \& Potter, 1995; Jolicœur, 1999), processing a target to the level of identification requires two discrete stages: (1) processing and representation of stimulus features and (2) sustained attention, resulting in consolidation of stimulus identity sufficient for recognition or report. ${ }^{1}$ While the first stage occurs automatically, the second requires substantial attentional resources and requires more time to complete. The time- and attention-consuming nature of stage two means that if $\mathrm{T} 2$ arrives before consolidation of T1 is completed, its own consolidation must wait for presently occupied attentional resources to become available (Chun \& Potter, 1995; Jolicœur, 1999). If processing of T1 outlasts T2's brief representation before it is overwritten by the subsequent stimulus in the RSVP stream, then encoding of T2 will fail, and T2 report accuracy will be reduced. Thus, such $\mathrm{AB}$ theories predict that prolonged processing of $\mathrm{T} 1$ at the consolidation stage will result in poor accuracy for $\mathrm{T} 2$.

Despite short stimulus exposures, there is evidence that word stimuli receive semantic analysis in RSVP during Stage 1 processing. For example, T2s that were blinked and unable to be reported were still able to prime semantically associated words presented after the RSVP stream (Shapiro, Driver, Ward, \& Sorensen, 1997), and the semantic relationship between words in RSVP streams has been shown to influence target performance (Maki, Frigen, \& Paulson, 1997). Barnard, Scott, Taylor, May, and Knightley (2004) showed that a to-be-ignored distractor word captured attention and reduced report accuracy for a subsequent target if the distractor word was semantically similar to the target category. Event-related brain potentials (ERPs) have also shown fully intact N400s for blinked T2s, suggesting complete semantic analysis of T2s that could not be reported (Luck, Vogel, \& Shapiro, 1996). Evidence for semantic activation of targets and distractors in RSVP streams has led researchers to investigate whether emotionally laden stimuli might receive preferential attentional processing when presented as RSVP targets or distractors.

There is reason to suspect that emotionally laden words may receive preferential processing in RSVP; several paradigms have shown evidence for preferential processing for some emotional materials under some conditions. When using clinical populations, research with paradigms such as Stroop (see Williams, Mathews, \& MacLeod, 1996, for a review) and dot probe (e.g., MacLeod, Mathews, \& Tata, 
1986) has demonstrated that clinical participants exhibit a compelling bias to attend to emotional words, particularly if they are consistent with their psychopathology. However, emotionally charged words show attentional effects less reliably in normal controls. In participant samples with no clinical psychopathology, sometimes emotionally charged words appear to be exempt from the usual attentional processing limitations, as they are able to capture attention in paradigms such as inattentional blindness (e.g., Mack \& Rock, 1998), dot probe (Mogg, Bradley, De Bono, \& Painter, 1997), Stroop (MacKay et al., 2004) and digit parity (Aquino \& Arnell, 2007). Imaging studies (Compton et al., 2003; Whalen, Bush, et al., 1998) and electrophysiological data (e.g., Stormark, Nordby, \& Hugdahl, 1995) have also provided evidence that the processing of emotional words may be amplified. However, normal control participants have sometimes failed to show attentional biases to emotionally laden words in paradigms such as Stroop (Gotlib \& McCann, 1984), dot probe (MacLeod et al., 1986), visual search (Harris, Pashler, \& Coburn, 2004), and digit parity (Harris \& Pashler, 2004). Therefore, there is currently no clear consensus about the conditions under which emotional stimuli affect attentional processing in normal individuals, nor about the nature of that effect.

\section{RSVP and Emotionally Charged Words}

Within the AB paradigm, emotionally charged words may be presented as $\mathrm{T} 1, \mathrm{~T} 2$, or a distractor in the RSVP stream. The latter two options have been studied quite extensively. Anderson and Phelps (2001) first observed that healthy control participants produced a smaller $\mathrm{AB}$ for arousing, negative T2 words, whereas patients with left or bilateral anterior temporal lobectomies that included removal of the amygdalae showed no reduction relative to nonemotional T2 words. Keil and Ihssen (2004) also showed a reduced $\mathrm{AB}$ for negative (and positive) verbs presented as $\mathrm{T} 2 \mathrm{~s}$ during the $\mathrm{AB}$ interval, but only when they were rated as arousing.

Emotion theorists agree on two fundamental dimensions reflected to varying degrees in all emotions, namely, valence and emotional arousal (e.g., Lang 1995; Lang, Greenwald, Bradley, \& Hamm, 1993; Russell, 1980; see also Mehrabian's pleasure/arousal/dominance model, 1991, 1997). However, in studies using emotionally laden words, it is often unclear which of the two major dimensions is most critically related to the observed results. For example, emotional Stroop and subliminal presentation studies have reported that negative information automatically attracts attentional resources (e.g., Dijksterhuis \& Aarts, 2003; Ito, Larsen, Smith, \& Cacioppo, 1998; Pratto \& John, 1991; see also Whalen, Rauch, et al., 1998). However, in a systematic investigation of emotional words as T2s in dual-task RSVP, Anderson (2005) reported that the $\mathrm{AB}$ was attenuated when sexual/taboo words were presented as $\mathrm{T} 2$. He also provided evidence that the arousal ratings of the words - rather than their valence ratings, word frequency, or distinctiveness - represented the critical factor in the AB attenuation. Anderson suggested that highly arousing $\mathrm{T} 2 \mathrm{~s}$ require less attention for successful identification and report, and are therefore less vulnerable to the attentional limitations that underlie the AB. Overall, $\mathrm{AB}$ studies have shown convincingly that arousing $\mathrm{T} 2$ words can overcome, at least in part, the attentional limitations that underlie the AB. In contrast, highly valenced T2 words that are less arousing appear to have no effect on the AB (Anderson, 2005; Keil \& Ihssen, 2004).

Emotional stimuli have also been presented as to-beignored distractors in the RSVP stream while participants search for a single target (e.g., Arnell, Killman, \& Fijavz, 2007; Barnard, Ramponi, Battye, \& Mackintosh, 2005; Most, Chun, Widders, \& Zald, 2005). By presenting the emotional stimuli at various temporal positions prior to the single target, one can use single-target accuracy to estimate the amount of attention given to the emotional stimulus. The results of these studies indicate that the presence of emotional distractors can capture attention at the expense of accuracy for subsequent, emotionally neutral targetsin effect setting off an involuntary $\mathrm{AB}$ (involuntary because the emotional stimulus was not a specified target). Most, Chun, et al. (2005) have demonstrated that a disturbing photo (e.g., a gory picture of a disgusting scene) presented in the RSVP stream as a to-be-ignored distractor captured participants' attention, reducing their accuracy on the subsequent, emotionally neutral picture target. Furthermore, this effect was greatest for participants who had scored high on a harm avoidance measure. Most, Smith, Cooter, Levy, and Zald (2007) showed a similar involuntary AB when erotic pictures were presented as distractors. Barnard and colleagues (2005) also investigated these attentional effects in RSVP, presenting threat words to participants with high or low anxiety levels. Threatening distractors reduced accuracy for subsequent neutral target words, but only in participants characterized by high-state and hightrait anxiety. Arnell et al. (2007) presented to unselected participants a sad, positive, threatening, taboo, or emotionally neutral word as a to-be-ignored distractor prior to an emotionally neutral target in RSVP. Their results showed that target accuracy was uniformly high when targets were preceded by a neutral, threatening, sad, or positive distractor, but was reduced when a taboo distractor appeared shortly before the target. Furthermore, they found that arousal ratings, but not valence ratings, of the emotional words predicted accuracy for subsequent targets.

Thus, arousing words presented as $\mathrm{T} 2$ attenuate the $\mathrm{AB}$, but arousing words presented as to-be-ignored distractors appear to initiate an involuntary $\mathrm{AB}$, with both findings suggesting that arousing words receive different attentional processing than less arousing words when presented in RSVP. However, no known studies to date have examined the impact, if any, of presenting emotional words as $\mathrm{T} 1$ in the AB paradigm. According to two-stage bottleneck models of the AB, T2 cannot be consolidated until T1 has been consolidated and the attentional bottleneck is cleared. If arousing words receive preferential attentional processing, then $\mathrm{T} 1$ may receive more attention at the expense of $\mathrm{T} 2$, resulting in a larger $\mathrm{AB}$ when $\mathrm{T} 1$ is emotionally arousing than when it is not. On the other hand, if fewer attentional resources are required to process emotionally arousing words, then T1 may clear the bottleneck more quickly, allowing earlier $\mathrm{T} 2$ processing and resulting in a smaller $\mathrm{AB}$. 


\section{The Present Study}

In the present study, we examined whether emotionally charged words can influence T2 report when the emotional word is voluntarily attended (presented as T1) and when it is not (presented as a to-be-ignored distractor). Including both conditions allowed us to test whether the words that commanded attention in one task were the same words that captured attention in the other. In the present study, we presented emotionally neutral, negative (sadness related), positive, sexual/taboo, and threatening words as T1 and examined the effect on report of a neutral $\mathrm{T} 2$ presented at various lags after T1. In a separate condition, these same words were presented as to-be-ignored distractors (pseudotarget) preceding a single to-be-reported target (as in Arnell et al., 2007). In addition, to isolate the effects of emotional arousal and valence on T2 report, we asked participants to provide ratings of emotional arousal and valence for each of the emotional words. A surprise recognition memory task was also given after the RSVP trials to examine which words had been encoded into memory. The effects of emotional words as T1s and pseudotarget were tested first in Experiment 1 using a within-participants design, followed by a second experiment using a between-participants design.

Sexual/taboo words have been shown to attenuate the $\mathrm{AB}$ when presented as T2 (Anderson, 2005; Anderson \& Phelps, 2001 ) and to set off an involuntary AB when presented as tobe-ignored distractors in single-target RSVP (Arnell et al., 2007). If these words do receive preferential attentional processing in RSVP, and T2 must wait until attention is freed from $\mathrm{T} 1$ to be consolidated, then we predict that a larger $\mathrm{AB}$ will be observed when sexual/taboo words are presented as T1 than when neutral words are. If these words require less attention, and attentional resources are quickly freed for processing of $\mathrm{T} 2$, then we expect that the $\mathrm{AB}$ will be smaller for sexual/taboo T1s. In either case, arousing words should be more likely than other words to be noticed and recognized after a short delay. Indeed, if memory for sexual/taboo words predicts accuracy for targets that follow, and recognition performance mediates the relationship between arousal and T2 accuracy, this will suggest that sexual/taboo words are preferentially encoded at the expense of subsequent neutral targets. Furthermore, we predict that the words that capture attention and set off an involuntary $\mathrm{AB}$ when presented as to-be-ignored distractors in the single-target RSVP paradigm will be the same words that hold attention and increase the $\mathrm{AB}$ when presented as $\mathrm{T} 1 \mathrm{~s}$ in the $\mathrm{AB}$ paradigm.

Arousal has been intrinsically linked to physiological reactions mediated by the amygdala (Anderson \& Phelps, 2001; Canli, Zhao, Brewer, Gabrieli, \& Cahill, 2000; Hamann, 2001; Kensinger \& Corkin, 2004; Vuilleumier, 2005). When the semantic representations of arousing words are activated at Stage 1 processing, the amygdala triggers processes that influence both the perceptual processing of these words and the amount of sustained attention allotted to them (Anderson \& Phelps, 2001; Cahill \& McGaugh, 1995; Canli et al., 2000; Hamann, 2001; Kensinger \& Corkin, 2004; LaBar \& Cabeza, 2006; Vuilleumier, 2005), resulting in more complete Stage 2 processing. In contrast, words that have high emotional valence but not high arousal show effects mediated by a frontotemporal memory network, not by the amygdala (see, e.g., Kensinger \& Corkin, 2004; LaBar \& Cabeza, 2006). As such, we anticipate independent effects for arousal ratings and valence ratings when predicting the magnitude of the $A B$ observed when a given word is presented as $\mathrm{T} 1$.

\section{EXPERIMENT 1}

\section{Method}

\section{Participants}

Twenty-two Brock University undergraduate students (19 female) participated in this study. They were tested individually in a single session lasting about $1.5 \mathrm{~h}$ and received partial course credit or a small honorarium for their time. All reported normal or corrected-to-normal vision and English as a first language. The study was reviewed by and received approval from the Brock University Research Ethics Board.

\section{Design}

The study was based on two RSVP paradigms, each constructed as a $5 \times 6$ factorial design. In one paradigm (the $\mathrm{AB}$ task), an emotion word (T1) and a target color name (T2) were both embedded in an RSVP stream of emotionally neutral noncolor words. There were five kinds of T1 words: neutral, negative, positive, or taboo, or one of the distractor words was presented as T1. One of 10 target color names appeared in one of six stream positions after the T1 word $(1,2,3$, 4,5 , or 8 words later), corresponding to time lags of $117,234,350$, 467, 583, and $933 \mathrm{msec}$, respectively. Whereas all other stimuli were presented in black, T1 was presented in red type. Participants were asked to report whether T1 appeared in capital or small letters, and also to identify the $\mathrm{T} 2$ color name embedded later in the stream. The levels of each factor varied randomly for each participant, but were constrained so that every possible combination of factors appeared equally often every 60 trials. The AB task consisted of 240 trials.

The second paradigm (the capture task) used the same design except that in this task, the emotion word presented as a $\mathrm{T} 1$ in the $\mathrm{AB}$ task became a to-be-ignored distractor printed in black uppercase letters like the other stimuli. For each trial, participants were asked only to name the color word embedded in the stream (target) and were not alerted to the presence of the emotion word. The capture task also consisted of 240 total trials.

\section{Apparatus and Stimuli}

All computer stimuli were presented via E-Prime software (Schneider, Eschman, \& Zuccolotto, 2002) on a Sony VAIO desktop computer with a 17-in. CRT color monitor. The refresh rate of the monitor was $60 \mathrm{~Hz}$, such that each word required seven frames for a presentation rate of $117 \mathrm{msec}$ per word. This presentation rate was chosen to produce fairly high levels of T2 performance on both the $\mathrm{AB}$ and capture tasks so that any reduction in $\mathrm{T} 2$ accuracy could be readily observed. Participants responded by keypress, using designated keys on the computer keyboard.

For the AB task, words were presented in RSVP format, in which each stimulus appeared in rapid succession in the same place on the screen. There were no blank interstimulus intervals (ISIs) between successive items. Each RSVP stream contained 18 items, including a first target (T1; a neutral, negative, positive, or taboo word, or one of the words from the distractor set), a target color word (T2), and 16 distractor words. The words subtended about $1.4^{\circ}$ of visual angle in height and $3.6^{\circ}$ to $7.2^{\circ}$ in width at an unfixed binocular viewing distance of approximately $40 \mathrm{~cm}$. All stream items were presented in black, 18-point bold Courier New font on an opaque white screen, with the exception of T1, which was presented in red. On half of the trials in each condition, the red $\mathrm{T} 1$ word was presented in small letters, and on the other half of the trials in each condition, the red T1 word was presented in capital letters. T1 appeared equally as often as the fifth or eighth item in the stream for each combination of T1 word type and lag. For neutral, negative, positive, and taboo trials, T1 was selected randomly from the appropriate list of 24 words (see Appendix A), ${ }^{2}$ with the constraint 
that each word was used once every 120 trials. A fifth T1 category consisted of 24 emotionally neutral words randomly drawn from the distractor set (Appendix B) and labeled "none." The "none" category was included to test whether target accuracy would differ for emotionally neutral words that were presented only twice for each task (i.e., words from the "neutral" category) and for emotionally neutral words that were presented approximately 80 times as distractors (i.e., words from the "none" category). Each T1 word was presented twice in the AB task. The neutral, negative, positive, and taboo words were adapted from the stimulus set used by Anderson (2005) and were between four and eight letters in length. Across conditions, T1 words were matched for word length $(5.13,5.42,5.74$, and 5.21 letters for neutral, negative, positive, and taboo words, respectively) and word frequency (17.83, 23.72, 29.00, and 27.14 per million, respectively, $F_{\mathrm{s}}<1$; Kučera \& Francis, 1967). ${ }^{3}$ On $20 \%$ of the trials, the emotion word was absent from the stream, and T1 was a word from the distractor pool that was presented in red. The distractors were 59 neutral-valence, low-arousal words from four to seven letters in length (see Appendix B). For each trial, distractors were chosen randomly from the set without replacement. There were 10 possible T2 color words (blue, green, silver, yellow, white, purple, pink, black, brown, and orange) that varied from four to six letters in length. T2 identity was chosen randomly on each trial, with the constraint that each color word was used equally often every 20 trials. See Figure 1 for a depiction of the AB task.

The stimuli for the capture task were identical to those for the $A B$ task, with the exception that the emotion word was now presented as a black distractor (pseudotarget) instead of as T1. All stream items were presented in black, uppercase 18-point bold Courier New font on an opaque white screen. See Figure 1 for a depiction of the capture task.

\section{Procedure}

Each participant was asked to perform five different tasks in a single session: (1) a brief questionnaire designed to ascertain the participant's mood in recent weeks; (2) the AB task; (3) the capture task;
(4) recognition memory tests for each of these RSVP tasks, where participants identified any $\mathrm{T} 1 \mathrm{~s}$ they recognized from the $\mathrm{AB}$ task and any pseudotarget they recognized from the capture task; and, finally, (5) a rating task in which participants rated T1s/pseudotargets for their valence and emotional arousal. The order of the capture and $\mathrm{AB}$ tasks was counterbalanced across participants.

Mood measure. On arrival at the lab, participants were asked to fill out the Hospital Anxiety and Depression Scale (HADS; Zigmond \& Snaith, 1983), which contained seven questions concerning the frequency of depression symptoms and seven questions concerning the frequency of anxiety symptoms. Participants received a score from 0 to 21 for depression symptoms and 0 to 21 for anxiety symptoms. Results from the mood measure are not reported here because they were not reliable across Experiments 1 and 2.

AB task. On each trial, participants were instructed to determine whether the lone red T1 word embedded in the RSVP stream was in capitals or small letters and identify the color name embedded in the stream following the red word. (The word "red" was never used as a target in either the $\mathrm{AB}$ or capture tasks.) Before beginning the experimental trials, participants were shown the 10 color names and informed that the target would always be from this set, and only these responses would be allowed. They were not informed that some of the T1 words would be emotionally laden, except for a very general warning in the consent form. Before beginning the first task, participants were allowed a few practice trials (average $<10$ ) with the same stimuli as were used in the experimental trials. Each trial began with the appearance of a fixation cross in the center of a blank screen for $500 \mathrm{msec}$, followed by a 500 -msec blank interval before the RSVP stream commenced. Immediately after each stream, participants were prompted by the computer to report whether the red word was presented in capital or small letters. "Capital" and "small" labels were affixed to the keyboard. After making their response, participants were then prompted by the computer to press a key indicating the identity of the target color name. (Color names were
A

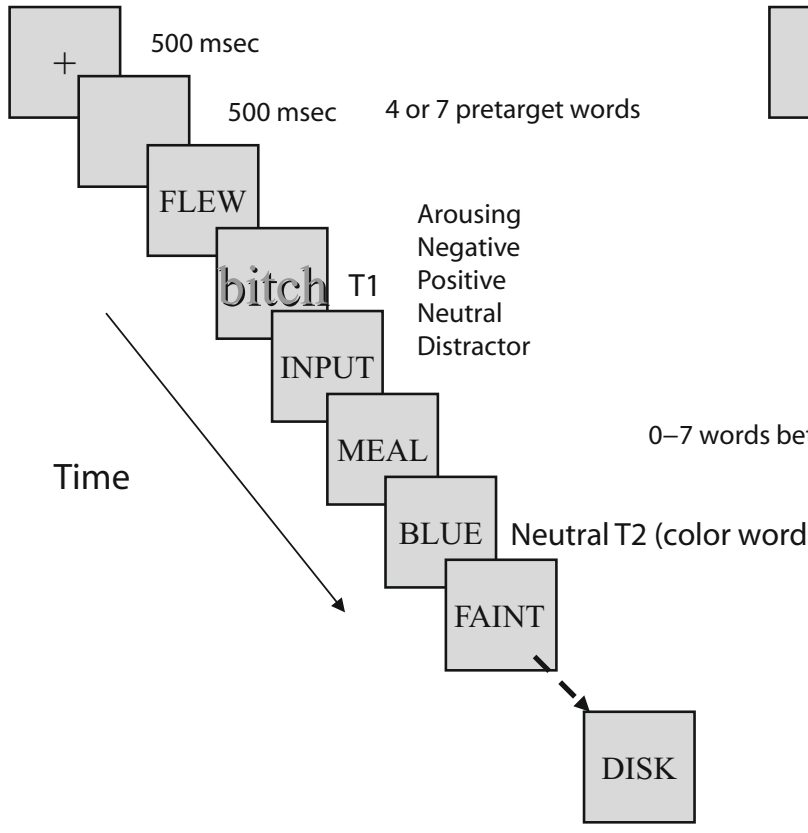

AB Task

18 stimuli
B

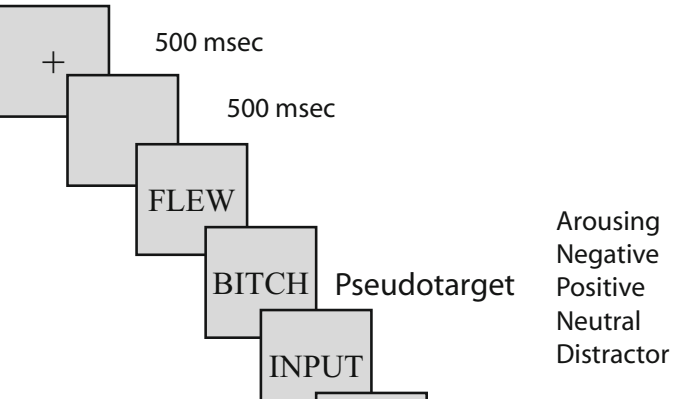

\section{Capture Task}

Figure 1. (A) The sequence of stimulus events within a stream for the AB task, Experiments 1 and 2. (B) The sequence of stimulus events within a stream for the capture task, Experiments 1 and 2. 
attached to 10 keys in the top letter row of the keyboard.) Participants were encouraged to guess if they were not certain of the color name, but to try to be accurate. Responses were not speeded. The fixation cross for the next trial appeared $2 \mathrm{sec}$ after the participant's keypress.

Capture task. Capture task procedures were the same as those used in the AB task, with the exception that, on each trial, participants were asked to identify the single-color target embedded in an RSVP stream and to ignore all other items in the stream. Participants were not informed that emotion words would be presented on some trials.

Recognition memory tests. After completing both the $\mathrm{AB}$ and capture tasks, participants were asked to complete two identical checklists, each containing the 96 words from Appendix A. Participants were told that some of the words had been presented as red targets in the $\mathrm{AB}$ task and/or as pseudotarget in the capture task. They were asked to identify with a check any words they recognized as having seen in the $\mathrm{AB}$ task in one list, and in the capture task in another list. In fact, all of the words on the recognition test lists had been presented twice as $\mathrm{T} 1 \mathrm{~s}$ in the $\mathrm{AB}$ task and twice as pseudotarget in the capture task. To minimize confusion, participants responded with a red pen when identifying $\mathrm{T} 1 \mathrm{~s}$ they recognized from the $\mathrm{AB}$ task (presented in red), and a black pen for identifying black pseudotarget from the capture task. They were asked to fill out the recognition test list for the most recently completed task first. Because the order of task administration was counterbalanced, any difficulty in recalling the most remote (earliest) task would be evenly distributed. Within each list, participants were allowed to go through each list at their own pace, in any order. They could check as many or as few words as they chose.

Word ratings. Participants were given a short break during instructions for the ratings task. There were 96 trials, in which all of the 96 emotion words from Appendix A (shown as T1s in the AB task and pseudotarget in the capture task) were presented in random order, balanced across word categories (negative, positive, taboo, neutral). Participants were instructed to rate each word's valence (very pleasant to very unpleasant) and arousing quality (very low to very high in emotional arousal) using 7-point Likert scales. With respect to arousal, participants were instructed to consider the magnitude of the reaction they felt when they read a word, regardless of what their reaction was based on. Each word remained on the screen with a word prompt indicating "valence" until the participant responded by pressing a number key from 1 to 7 for the valence rating. The same word then remained on the screen, but the prompt was changed to "arousal." The "arousal" prompt and the word remained on the screen until the participant pressed a key from 1 to 7 for that word's arousal rating. Participants were encouraged to consider their subjective reactions to these words carefully and to rate the words using the whole scale.

\section{Results}

\section{Manipulation Check}

Before beginning the main analyses, we wanted confirmation that our assessment of words as being neutral, negative, positive, or taboo was also shared by participants. Separate one-way ANOVAs of participants' valence and arousal ratings indicated significant effects of word type for each dimension [valence, $F(3,92)=84.89, p<$ $.001, \eta^{2}=.74$; arousal, $F(3,92)=90.53, p<.001, \eta^{2}=$ .75]. Bonferroni-corrected pairwise comparisons in each analysis indicated that words of each word type were rated differently from all other word types for both arousal and valence (all $p s<.02$ ). Figure 2 shows a two-factor plot of the mean arousal and valence ratings for each of these words, collapsed across participants. Each word is coded by a symbol representing its type. From this graph, it is clear that participants generally agreed with our experi- mental groupings of words as being negative, positive, taboo, or neutral. The "none" category is not represented in the graph because it consisted of words randomly selected from the 60 neutral distractors, and these words were not rated.

\section{AB Task}

Target identification. Figure 3 shows the mean T2 accuracy (\% correct responses) in the AB task for each $\mathrm{T} 1$ emotion condition, as a function of the lag between $\mathrm{T} 1$ and T2. In all experiments, T2 accuracy was calculated for T1-correct trials only; however, the same data patterns were observed for all analyses herein when T2 accuracy was not conditionalized on T1 accuracy. A repeated measures ANOVA was performed on T2 accuracy rates with lag and T1 word type as factors (see Table 1 for all results from this ANOVA). Pairwise comparisons confirmed that T2 accuracy was lower in the $\mathrm{T} 1$ taboo condition $(M=65.1 \% \pm 3.1 \%)$ in relation to each of the other T1 word types (all $M \mathrm{~s}>75 \%$, all $p \mathrm{~s}<.001$ ). No other comparisons were significant (all $p \mathrm{~s}>.90$ ). The effect of T1 emotion type differed by lag for the interaction. Pairwise comparisons indicated a significant difference between T2 accuracy on neutral trials and T2 accuracy on taboo trials at lags 3 and $4(p s<.01)$, suggesting that the taboo words presented early in the RSVP stream disrupted processing of neutral targets arriving between about $351-468 \mathrm{msec}$ after the presentation of the taboo word. However, there were no other significant differences in T2 accuracy for neutral trials versus any other emotion type at any lag (all $p \mathrm{~s}>.05)$.

When task order (AB task performed before or after the capture task) was added as a factor to the above analyses, all original effects remained unchanged, and a significant

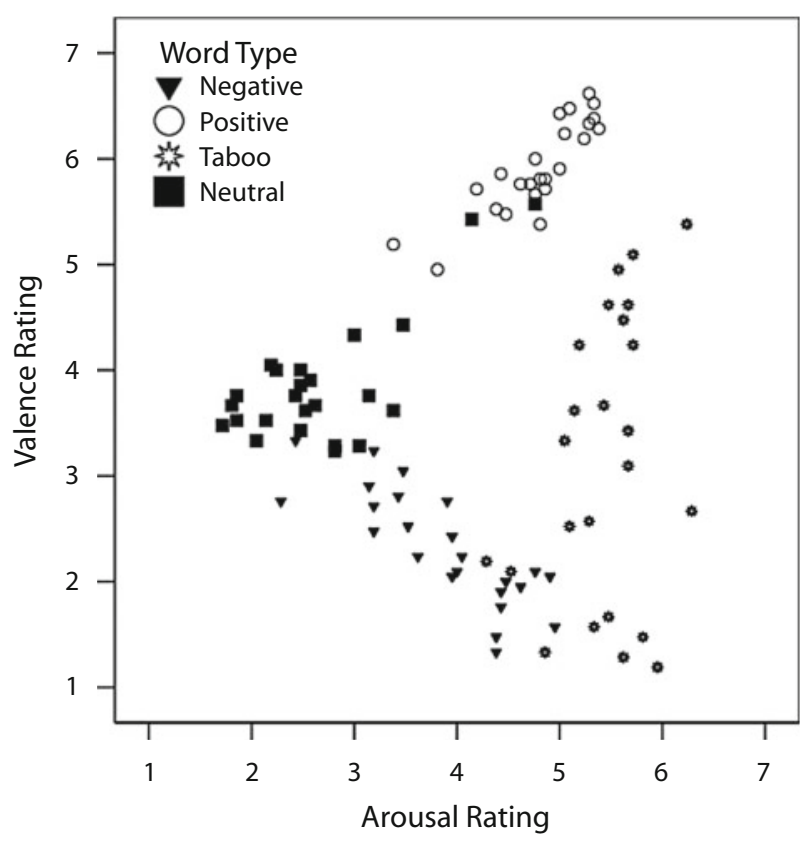

Figure 2. Two-factor plot of the mean arousal and mean valence ratings for each of the 96 pseudotarget/T2 words (collapsed across participants) in Experiment 1. 


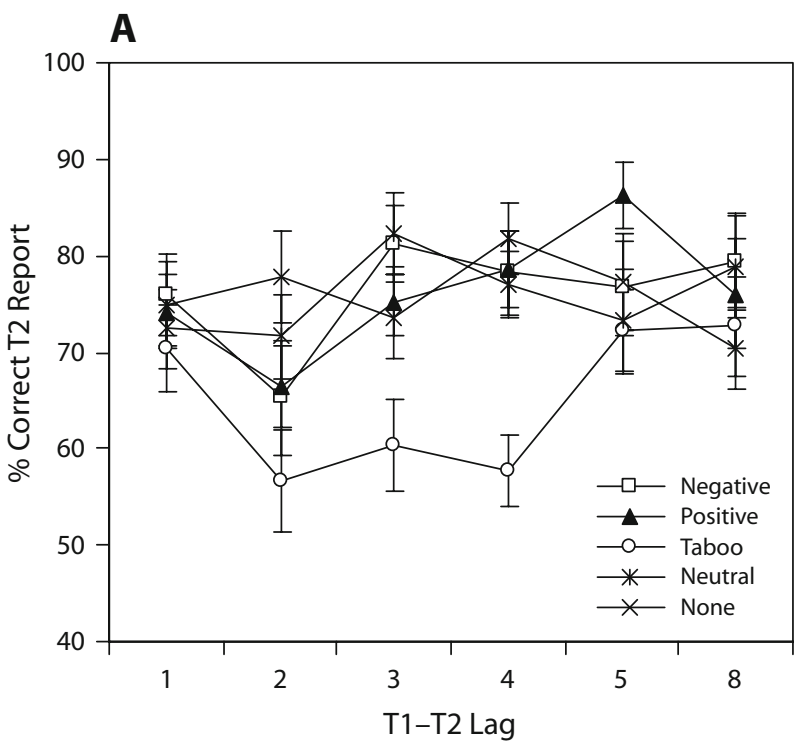

B

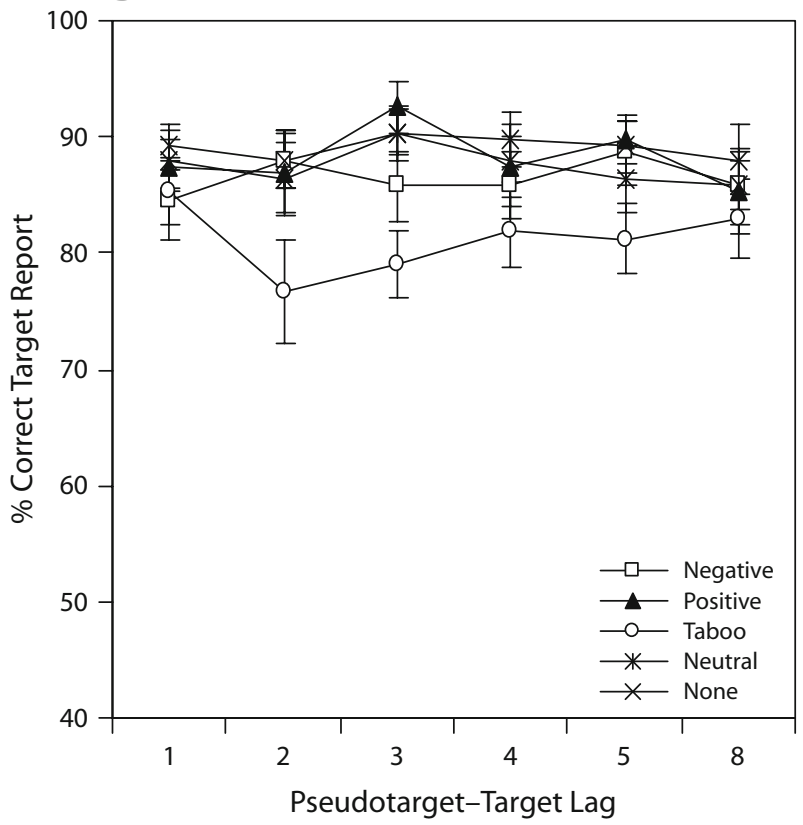

Figure 3. (A) The mean percentage of correct $\mathrm{T} 2$ responses as a function of $\mathrm{T} 1$ word type and the lag between $\mathrm{T} 1$ and $\mathrm{T} 2$ in the AB task, Experiment 1. Error bars represent the standard error for each mean. (B) The mean percentage of correct target responses as a function of pseudotarget word type and the lag between pseudotarget and targets in the capture task, Experiment 1. Error bars represent the standard error for each mean.

order $\times$ lag interaction was also observed $[F(5,100)=$ $3.06, p<.05]$, in which the lag effect was larger for participants who performed the $\mathrm{AB}$ task second. No interactions including $\mathrm{T} 1$ emotion type and order were significant ( $p$ s > .34), indicating similar effects of emotion words for both task orders.

T1 accuracy was $95.4 \%(S E=.79)$ overall and was unaffected by $\mathrm{T} 1$ emotion word type, lag, or their interaction (all $p s>.20)$.
Word ratings and $\mathbf{T} 2$ identification. Relationships among arousal, valence, and $\mathrm{T} 2$ accuracy in the AB task were examined using the participants' arousal and valence ratings for each of the emotion words presented as T1s. For each of the 96 emotion words, mean valence ratings and mean arousal ratings were calculated by averaging ratings for each word across participants. The average accuracy of T2, collapsed across participants, was also calculated separately for trials using each T1 emotion word. The average arousal and valence ratings for each emotion word were then correlated with mean T2 accuracy on trials where that emotion word was presented as T1. For example, the mean arousal and valence ratings for the word murder were examined with respect to T2 accuracy on trials where murder was presented as T1. Results of these analyses indicated that $\mathrm{T} 1$ arousal ratings were associated with reduced T2 accuracy (see Table 2 for all zero-order correlations) even when valence ratings were covaried out [partial $r=-.44, t(93)=4.78, p<.001$ ]. Therefore, T1s with higher arousal ratings were associated with lower accuracy for the neutral T2s that followed them. Valence ratings for T1 words did not predict T2 accuracy. However, if the emotional valence of 11 was related to the $A B$, it may be that valence extremity (very high positive or negative valence compared with neutral valence) would be a better predictor than valence ratings from negative to positive. To examine any potential relationships with valence extremity, the valence rating for each word was subtracted from 4 (the midpoint on the valence scale), and the absolute difference was used as a predictor of T2 performance. Valence extremity did not significantly predict $\mathrm{T} 2 \mathrm{accu}-$ racy. However, when arousal ratings and valence extremity values were entered as simultaneous predictors of $\mathrm{T} 2$ accuracy, both arousal and valence extremity explained significant unique variability in T2 accuracy (see Table 3 ). Therefore, once variability due to arousal was accounted for, valence extremity did predict $\mathrm{T} 2$ accuracy, but words with more extreme valence were associated with higher, not lower, $\mathrm{T} 2$ accuracy.

Recognition hit rates and $\mathbf{T} 2$ identification. $\mathrm{T} 1 \mathrm{~s}$ with high arousal ratings were associated with poor accuracy for subsequent target information. This may have been because the taboo $\mathrm{T} 1 \mathrm{~s}$ occupied attentional resources more fully, thereby reducing consolidation of T2. If so, it is more likely that taboo T1s would be identified in the recognition lists as remembered, in relation to other kinds of words. To test this, the recognition hit rate (mean number of checks) for T1 words was compared in each of the conditions of the $\mathrm{AB}$ task. The mean number of hits was 3.3 for neutral words, 3.6 for negative words, 4.0 for positive words, and 11.2 for taboo words. A one-way ANOVA confirmed that recognition hits differed significantly across T1 word types $[F(3,92)=56.02, p<.001]$. Pairwise comparisons indicated that taboo words were recognized significantly more often than words of any other type $(p \mathrm{~s}<.001)$, and that the hit rate was the same for all other word types (all $p \mathrm{~s}>.90$ ).

The total number of recognition hits that each of the 96 T1 words received was summed across participants (maximum $N=22$ ). The number of hits each word received was 
Table 1

ANOVAs on Target Accuracy by Experiment and Task

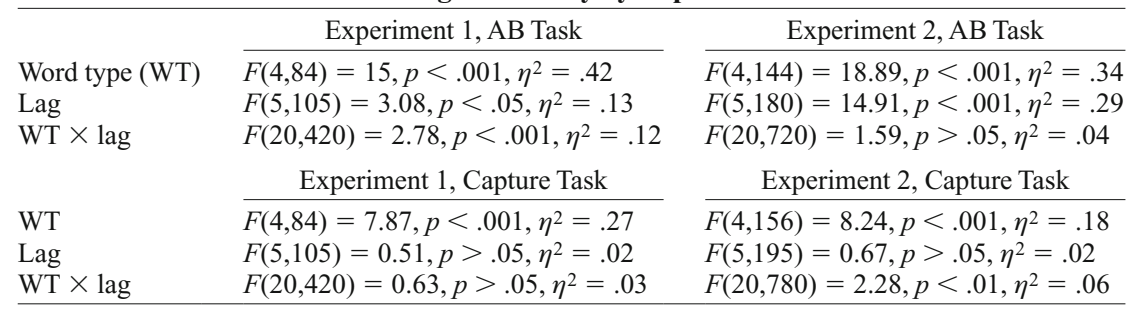

then correlated with T2 color accuracy on trials where that word was presented as T1. The correlation revealed a significant negative relationship in which better recognition of a $\mathrm{T} 1$ in the $\mathrm{AB}$ task was associated with impaired accuracy for the subsequent T2 (see Table 2). There was a positive correlation between the arousal rating of a word and its hit rate - that is, words rated higher in arousal had more recognition hits. Neither valence ratings nor valence extremity predicted the recognition hits for a word. However, when standardized T1 arousal and valence extremity ratings were entered as simultaneous predictors in a regression on recognition hits for T1 words, both arousal and valence extremity accounted for significant unique variance in recognition, but in opposite directions. T1 words that received higher arousal ratings were better recognized, but $\mathrm{T} 1$ words with extreme valence were not well recognized (see Table 4).

Arousal ratings and recognition hits for $\mathrm{T} 1 \mathrm{~s}$ were entered together as predictors in a single step in a regression analysis on T2 accuracy. Whereas recognition hits for T1 negatively predicted T2 accuracy, even when arousal rating was partialled out (see Table 5), arousal alone did not predict T2 accuracy when variability due to recognition for T1 was removed. This pattern suggests a direct relationship between $\mathrm{T} 1$ recognition and $\mathrm{T} 2$ accuracy, as well as an indirect relationship between arousal rating for $\mathrm{T} 1$ and $\mathrm{T} 2$ accuracy that was mediated by $\mathrm{T} 1$ recognition (see Figure 4).

\section{Capture Task}

Target identification. Figure 3 illustrates the mean color target accuracy ( $\%$ correct responses) for each pseudotarget word type (neutral, negative, positive, taboo, and none) as a function of the lag between the pseudotarget and the target (see Table 1 for ANOVA results). Pairwise comparisons showed lower overall accuracy in the taboo condition $(M=81.2 \% \pm 1.6 \%)$ in comparison with each of the other four pseudotarget conditions (all $M \mathrm{~s}>86 \%$, all $p \mathrm{~s} \leq .05)$, but produced no other significant comparisons.

All previous effects were unchanged when task order (the capture task performed before or after the $\mathrm{AB}$ task) was added as a factor to the above ANOVA, and there were no main effects or interactions with the task order factor (all $p \mathrm{~s}>.25$ ), indicating similar effects of the emotion words for both task orders.

Word ratings and target identification. As in the $A B$ task, target accuracy in the capture task was not associated with valence ratings or valence extremity, but higher arousal ratings were associated with poorer identification of subsequent color targets (see Table 2). This finding did not change when valence ratings were covaried out [partial $r=-.31, t(93)=3.15, p<.01]$. As in the AB task, both arousal and valence extremity uniquely predicted target accuracy when examined together in a simultaneous regression. However, words with higher arousal were again associated with lower target accuracy, and those with more extreme valence were associated with higher target accuracy (see Table 3).

Recognition hit and target identification. A oneway ANOVA on pseudotarget recognition showed that mean recognition hits differed significantly across the

Table 2

Correlations Among Ratings, First-Target Recognition, and Second-Target Accuracy (Pearson's $r$ )

\begin{tabular}{|c|c|c|c|c|c|c|c|c|}
\hline \multirow{5}{*}{$\begin{array}{l}\text { Valence } \\
\text { Arousal } \\
\text { Valence extremity } \\
\text { T2 accuracy }\end{array}$} & \multicolumn{4}{|c|}{ Experiment $1, \mathrm{AB}$ Task } & \multicolumn{4}{|c|}{ Experiment 2, AB Task } \\
\hline & Arousal & $\begin{array}{l}\text { Valence } \\
\text { Extremity }\end{array}$ & $\begin{array}{c}\mathrm{T} 2 \\
\text { Accuracy }\end{array}$ & $\begin{array}{c}\mathrm{T} 1 \\
\text { Recognition }\end{array}$ & Arousal & $\begin{array}{l}\text { Valence } \\
\text { Extremity }\end{array}$ & $\begin{array}{c}\mathrm{T} 2 \\
\text { Accuracy }\end{array}$ & $\begin{array}{c}\text { Corrected } \\
\text { T1 Recognition }\end{array}$ \\
\hline & .16 & $\begin{array}{l}-.05 \\
.57^{* * *}\end{array}$ & $\begin{array}{c}.11 \\
-.42^{* * *} \\
.02\end{array}$ & $\begin{array}{l}-.14 \\
.55^{* * *} \\
-.03 \\
-.57^{* * *}\end{array}$ & $-.14^{*}$ & $\begin{array}{c}-.16^{*} \\
.34^{* * *}\end{array}$ & $\begin{array}{l}-.04 \\
-.23^{* * *} \\
.15^{*}\end{array}$ & $\begin{aligned} & .02 \\
& .48^{* * *} \\
&-.08 \\
&-.45^{* * *}\end{aligned}$ \\
\hline & \multicolumn{4}{|c|}{ Experiment 1, Capture Task } & \multicolumn{4}{|c|}{ Experiment 2, Capture Task } \\
\hline & Arousal & $\begin{array}{l}\text { Valence } \\
\text { Extremity }\end{array}$ & $\begin{array}{c}\text { Target } \\
\text { Accuracy }\end{array}$ & $\begin{array}{c}\text { PT } \\
\text { Recognition } \\
\end{array}$ & Arousal & $\begin{array}{l}\text { Valence } \\
\text { Extremity }\end{array}$ & $\begin{array}{c}\text { Target } \\
\text { Accuracy }\end{array}$ & $\begin{array}{c}\text { Corrected } \\
\text { PT Recognition }\end{array}$ \\
\hline $\begin{array}{l}\text { Valence } \\
\text { Arousal } \\
\text { Valence extremity } \\
\text { Target accuracy }\end{array}$ & .16 & $\begin{array}{l}-.05 \\
.57^{* * *}\end{array}$ & $\begin{array}{l}.07 \\
-.30^{* *} \\
.05\end{array}$ & $\begin{aligned} & .001 \\
& . 52^{* * *} \\
&- .04 \\
&- .42^{* * *} \\
&\end{aligned}$ & -.10 & $\begin{array}{l}-.16^{*} \\
.45^{* * *}\end{array}$ & $\begin{array}{l}-.11 \\
-.21^{* *} \\
.15^{*}\end{array}$ & $\begin{array}{l}.04 \\
.33^{* * *} \\
-.17^{* *} \\
-.27^{* * *} \\
\end{array}$ \\
\hline
\end{tabular}

Note-T1, first target; T2, second target; PT, pseudotarget. $\quad{ }^{*} p<.05 . \quad{ }^{* *} p<.01 . \quad{ }^{* * *} p<.001$. 
Table 3

Simultaneous Regression Analyses of Valence Extremity and Arousal on Second-Target Accuracy

\begin{tabular}{|c|c|c|c|c|}
\hline Predictors & $\beta$ & $R^{2}$ & $F$ & $t$ Values \\
\hline \multicolumn{5}{|c|}{ Experiment 1} \\
\hline \multicolumn{5}{|l|}{ T2 Accuracy (AB) } \\
\hline Complete model & & .27 & $17.44^{* * *}$ & \\
\hline Valence extremity & .38 & & & $3.53^{* *}$ \\
\hline Arousal & -.63 & & & $-5.90^{* * *}$ \\
\hline \multicolumn{5}{|c|}{ Target Accuracy (Capture) } \\
\hline Complete model & & .16 & $8.53^{* * *}$ & \\
\hline Valence extremity & .32 & & & $2.74^{* *}$ \\
\hline Arousal & -.48 & & & $-4.10^{* * *}$ \\
\hline \multicolumn{5}{|c|}{ Experiment 2} \\
\hline \multicolumn{5}{|l|}{ T2 Accuracy (AB) } \\
\hline Complete model & & .12 & $15.70^{* * *}$ & \\
\hline Valence extremity & .27 & & & $4.08^{* * *}$ \\
\hline Arousal & -.33 & & & $-5.01^{* * *}$ \\
\hline \multicolumn{5}{|c|}{ Target Accuracy (Capture) } \\
\hline Complete model & & .12 & $16.34^{* * *}$ & \\
\hline Valence extremity & .31 & & & $4.52^{* * *}$ \\
\hline Arousal & -.35 & & & $-5.15^{* * *}$ \\
\hline
\end{tabular}

pseudotarget types $[F(3,92)=22.67, p<.001] ; M=3.5$ for neutral words, 3.8 for negative words, 4.6 for positive words, and 8.3 for taboo words. Taboo words were recognized significantly more often than words of any other type (all $p \mathrm{~s}<.001$ ), and the number of hits was the same for all other word types (all $p \mathrm{~s}>.50$ ).

The total number of recognition hits received by each of the 96 pseudotargets was summed across participants and correlated with color target accuracy on trials where that word appeared as a pseudotarget. Increased recognition hits for a pseudotarget were associated with significantly impaired accuracy for a subsequent color target (see Table 2). Thus, for those pseudotarget that were later recognized, secondary targets were less likely to be identified during RSVP. This is consistent with the notion that, during RSVP, attention had been captured by arousing distractors, making it less available for the processing or encoding of target information that followed. Again, there was a significant positive relationship between arousal ratings and recognition memory. As in the AB task, there was no relationship between valence or valence extremity and recognition of pseudotarget. However, when variability due to arousal was accounted for, valence extremity also negatively predicted pseudotarget recognition (see Table 4).

Recognition of the pseudotarget was negatively related to target accuracy in simultaneous regression, even when the variability due to arousal rating was removed (see Table 5). However, arousal ratings did not predict target accuracy once recognition memory had been partialled out. Thus, as in the AB task, the analysis is consistent with an entirely mediated model in which the relationship between arousal and accuracy for subsequent targets depends on the arousing words' being processed sufficiently for later recognition (see Figure 4).

Cross-task comparisons. Two additional results were of interest. A correlational analysis revealed that emotion words that were more likely to be recognized in the $\mathrm{AB}$ task were also more likely to be recognized in the capture task $[r(94)=.80, p<.001]$. Also, emotion words that led to $\mathrm{T} 2$ report failure in the $\mathrm{AB}$ task were roughly the same emotion words that led to target report failure in the capture task $[r(94)=.50, p<.001]$. Overall, the same emotion words were recognized at the expense of subsequent color targets whether these emotion words were presented as targets that required a response in the $\mathrm{AB}$ task, or as to-be-ignored distractors in the capture task.

\section{Discussion}

In Experiment 1, we examined the effect of emotional words on the identification of closely following, neutral target words in dual-task and single-task RSVP procedures. Whether the emotion word was presented as a first target in the $\mathrm{AB}$ task or as a to-be-ignored distractor in the second task, the same taboo words were found to reduce accuracy for subsequent emotionally neutral targets. Arousal ratings and valence extremity for the emotional words predicted accuracy for trailing targets in both RSVP tasks, where poor target accuracy was associated with high arousal and low valence extremity. Taboo words were also recognized more often than were other word types in a posttest recognition task. On the basis of analyses showing that recognition memory mediates the relationship between arousal and target accuracy, we suggest that the arousing quality of taboo T1 words and pseudotarget led to more attention to these words, resulting in poorer identification of T2s.

\section{EXPERIMENT 2}

For both tasks in Experiment 1, the relationship between arousal ratings of the emotion words and accuracy for targets trailing the emotion words was found to be wholly mediated by recognition of the emotion words. Thus, it was prudent to ask in Experiment 2 whether the taboo items identified by participants as remembered were genuinely recognized

Table 4

Simultaneous Regression Analyses of Valence Extremity and Arousal on First-Target Recognition

\begin{tabular}{|c|c|c|c|c|}
\hline Predictors & $\beta$ & $R^{2}$ & $F$ & $t$ Values \\
\hline \multicolumn{5}{|c|}{ Experiment 1} \\
\hline \multicolumn{5}{|l|}{ T1 Recognition (AB) } \\
\hline Complete model & & .48 & $43.45^{* * *}$ & \\
\hline Valence extremity & -.51 & & & $-5.66^{* * *}$ \\
\hline Arousal & .84 & & & $9.31^{* * *}$ \\
\hline \multicolumn{5}{|c|}{ Pseudotarget Recognition (Capture) } \\
\hline Complete model & & .43 & $35.61^{* * *}$ & \\
\hline Valence extremity & -.49 & & & $-5.20^{* * *}$ \\
\hline Arousal & .80 & & & $8.43^{* * *}$ \\
\hline
\end{tabular}

Experiment 2

Corrected T1 Recognition (AB)

$\begin{array}{lrrrr}\text { Complete model } & & .30 & 50.54^{* * *} & \\ \text { Valence extremity } & -.28 & & & -4.78^{* * *} \\ \text { Arousal } & .58 & & 9.95^{* * *}\end{array}$

Corrected Pseudotarget Recognition (Capture) Complete model

Valence extremity $.2335 .71^{* * *}$

Arousal

$-.40$

.50

$-6.21^{* * *}$

$7.90^{* * *}$ 
Table 5

Simultaneous Regression Analyses of First-Target Recognition and Arousal on Second-Target Accuracy

\begin{tabular}{|c|c|c|c|c|}
\hline Predictors & $\beta$ & $R^{2}$ & $F$ & $t$ Values \\
\hline \multicolumn{5}{|c|}{ Experiment 1} \\
\hline \multicolumn{5}{|l|}{ T2 Accuracy (AB) } \\
\hline Complete model & & .34 & $24.32^{* * *}$ & \\
\hline T1 memory & -.49 & & & $-4.88^{* * *}$ \\
\hline Arousal & -.15 & & & -1.46 \\
\hline \multicolumn{5}{|l|}{ Target Accuracy (Capture) } \\
\hline Complete model & & .18 & $10.33^{* * *}$ & \\
\hline Pseudotarget memory & -.36 & & & $-3.29^{* *}$ \\
\hline Arousal & -.11 & & & -.98 \\
\hline \multicolumn{5}{|c|}{ Experiment 2} \\
\hline \multicolumn{5}{|l|}{ T2 Accuracy (AB) } \\
\hline Complete model & & .21 & $30.86^{* * *}$ & \\
\hline Corrected $\mathrm{T} 1$ recognition & -.44 & & & $-6.73^{* * *}$ \\
\hline Arousal & -.02 & & & -.32 \\
\hline \multicolumn{5}{|l|}{ Target Accuracy (Capture) } \\
\hline Complete model & & .09 & $11.62^{* * *}$ & \\
\hline Corrected pseudotarget recognition & -.22 & & & $-3.38^{* *}$ \\
\hline Arousal & -.14 & & & $-2.15^{*}$ \\
\hline
\end{tabular}

from the task or whether they had simply been checked because of their titillating nature. In this experiment, the recognition test lists contained foils for each word type, as well as the emotion word targets presented during the RSVP task. To rule out stimulus effects, words that were targets for half of the participants were foils for the other half, and vice versa. If participants recognize more taboo words from the task they completed, they should identify these words more often than other word types but show relatively few false alarms to taboo foils presented in the recognition test list. In addition, an effect of word type should be evident in the corrected recognition scores (hits minus false alarms). We also tested the relationship between the corrected recognition scores and subsequent target accuracy.

In addition, the fact that each participant had performed both the $\mathrm{AB}$ and capture tasks in Experiment 1 may have made it difficult for them to correctly identify the paradigm in which they had seen various words, despite the provision of color-coordinated pens for each recognition test list (red for $\mathrm{AB}$, black for capture). To eliminate any possibility of source confusion in recognition memory between the two paradigms, the $\mathrm{AB}$ and capture tasks were presented in Experiment 2 to two different groups of participants in a between-participants design.

Finally, the "none" category of T1 words and pseudotarget was removed, given that the neutral and "none" results did not differ in Experiment 1. It was replaced with a separate category for threat words because it was unclear whether threat/fear words (e.g., murder) or sexual/taboo words were responsible for the increased AB and capture effects observed for the taboo category in Experiment 1. The small number of threat words (5 of 24) was removed from the original taboo list and added to a separate threat category. These words were replaced with additional salacious words related to sex or with words that had a taboo quality in the new sexual/taboo condition for Experiment 2.

\begin{abstract}
Method

\section{Participants}

Seventy-eight additional undergraduate students ( 54 female) from Brock University participated in this study. Participants were tested individually for over $1 \mathrm{~h}$ and given credit toward their coursework or a small honorarium. Thirty-eight participants performed the $\mathrm{AB}$ task, and 40 performed the capture task.
\end{abstract}

\section{Design, Stimuli, and Procedure}

The design, stimuli, and procedure of Experiment 2 were identical to those of Experiment 1, with three exceptions. First, participants were assigned in a pseudorandomized fashion to perform either the $\mathrm{AB}$ task or the capture task, according to the order in which they arrived for the study. Second, all participants received a single recognition test list containing all 240 words used as T1s or pseudotarget in the RSVP tasks. However, in this experiment, half of the participants received 120 of these words ( 24 from each emotion category) twice in the RSVP task, and the remaining 120 words were memory foils that had not been presented in the RSVP task. The other half of the participants for each RSVP task received the opposite set of words as targets and foils (i.e., if murder was presented in the RSVP stream and was therefore a memory target for Participant 1 , then it was not presented in the RSVP stream for Participant 2 and was therefore a memory foil). Participants provided arousal and valence ratings for all 240 emotion words (targets and foils). Third, the emotion words were now neutral, negative, positive, physically threatening, or sexual/taboo (see Appendix C).

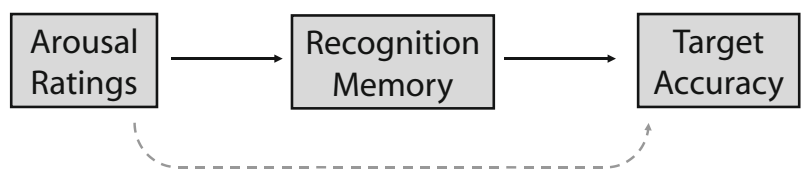

Figure 4. Model showing the relationships among target accuracy, arousal ratings for the emotion word, and recognition of the emotion word. The results suggest that the relationship between arousal rating and target accuracy is mediated by encoding of the emotion words. 


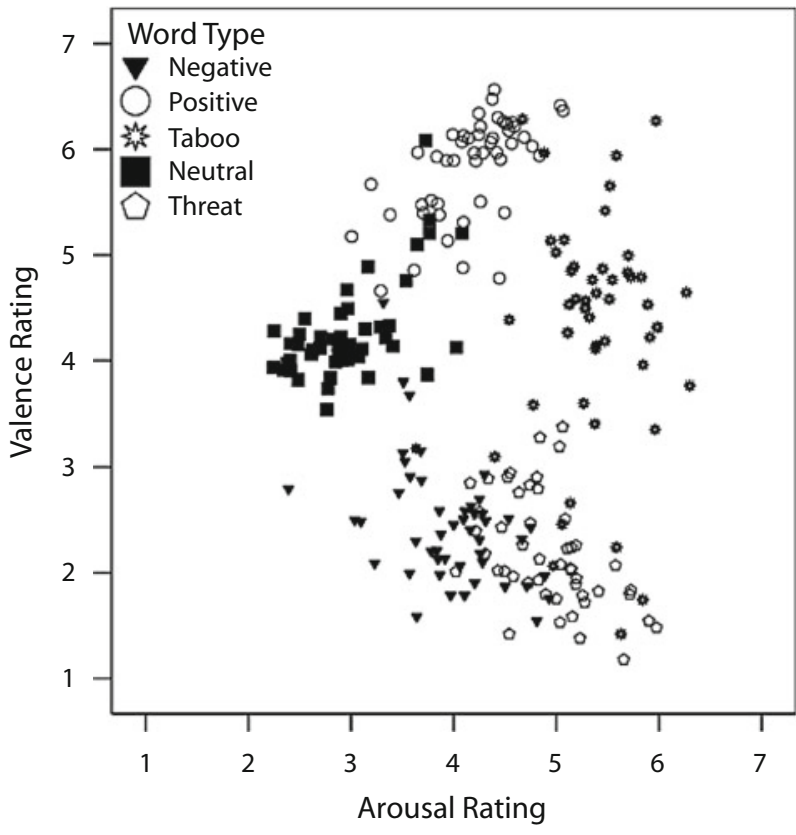

Figure 5. Two-factor plot of the mean arousal and mean valence ratings for each of the 240 pseudotarget/T1 words (collapsed across the two participant groups), Experiment 2.

\section{Results}

\section{Manipulation Check}

Figure 5 shows a two-factor plot of the mean arousal and valence ratings for the words from Appendix C. As indicated by the graph and separate one-way ANOVAs, participants' valence and arousal ratings confirmed the categorizations used [valence ${ }_{\mathrm{AB}}, F(4,235)=208.21, p<.001$, $\eta^{2}=.78 ; \operatorname{arousal}_{\mathrm{AB}}, F(4,235)=141.37, p<.001, \eta^{2}=$ .71 ; valence Capture $_{1}, F(4,235)=233.99, p<.001, \eta^{2}=.80$; arousal $\left._{\text {Capture }}, F(4,235)=153.04, p<.001, \eta^{2}=.72\right]$. All word types were rated differently from each other, except that negative and threat words did not differ on valence and positive and negative words did not differ on arousal.

\section{AB Task}

Target identification. The mean T2 color target accuracy ( $\%$ correct responses) for each T1 word type (neutral, negative, positive, sexual/taboo, and threatening) is presented in Figure 6 as a function of the lag between T1 and T2 (see Table 1 for ANOVA results). Pairwise comparisons confirmed that overall T2 accuracy was lower in the sexual/taboo condition $(M=64 \% \pm .03 \%)$ than in all other conditions (all $M \mathrm{~s}>73 \%$ ), which did not differ from each other $(p \mathrm{~s}>.90)$.

T1 accuracy was $93 \%(S E=.01)$ and was affected neither by word type nor the word type $\times$ lag interaction $(p \mathrm{~s}>.30)$. There was a main effect of lag $[F(5,185)=$ 4.01, $p<.01, \eta^{2}=.10$ ], but no pairwise comparisons were significant.

Word ratings and $\mathrm{T} 2$ identification. $\mathrm{T} 1$ arousal ratings and valence extremity were again related to T2 accuracy, but valence ratings were not (see Table 2). As in Experiment 1, simultaneous regression revealed that high arousal ratings for $\mathrm{T} 1$ words were associated with lower T2 color word accuracy, whereas more extreme valence ratings for $\mathrm{T} 1$ words were associated with higher $\mathrm{T} 2 \mathrm{ac}-$ curacy (see Table 3 ).

Recognition memory and $\mathbf{T} 2$ identification. The mean number of recognition hits awarded to words presented in the AB task was 2.7 for neutral words, 3.9 for negative words, 3.8 for positive words, 4.7 for threatening words, and 11.3 for sexual/taboo words. The mean number of hits differed by word type $[F(4,235)=76.44, p<$ $.001]$. Sexual/taboo words were more likely to be recognized than neutral or threatening words $(p s<.001)$, and threat words were more likely to be recognized than neutral words $(p<.01)$. The mean number of foil errors (false alarms) was 0.9 for neutral words, 2.0 for negative words, 2.0 for positive words, 2.0 for threatening words, and 2.4 for sexual/taboo words. The number of false alarms differed by word type $[F(4,235)=5.80, p<.001]$ only because neutral words were less likely to be recognized in error than the other word types $(p \mathrm{~s}<.03)$, which did not differ (all $p \mathrm{~s}>.90)$. Sexual/taboo foils did not receive more false alarms than other emotion word types.

A corrected recognition score for each word was calculated as hits minus false alarms for that word. The mean recognition score for T1 words was 1.77 for neutral words, 1.90 for negative words, 1.75 for positive words, 2.71 for threatening words, and 8.90 for sexual/taboo words $[F(4,235)=54.96, p<.001]$. Sexual/taboo words were recognized more often than other words ( $p$ s $<.001)$, but there were no differences in corrected recognition for the other word types (all $p \mathrm{~s}>.90$ ).

As in Experiment 1, higher arousal ratings in the $A B$ task were associated with increased corrected recognition memory scores for T1 words (see Table 2), but neither valence nor valence extremity was correlated with corrected recognition scores. However, both $\mathrm{T} 1$ arousal and valence extremity ratings accounted for significant unique variance in corrected recognition memory in simultaneous regression analyses, but in opposite directions, consistent with Experiment 1 (see Table 4).

Simultaneous regression showed that better corrected recognition for $\mathrm{T} 1$ words was associated with poor T2 report accuracy, whereas arousal alone did not predict $\mathrm{T} 2$ accuracy once the variability due to recognition for $\mathrm{T} 1$ was removed (see Table 5). These results follow the pattern found in Experiment 1-that is, a direct relationship existed between $\mathrm{T} 1$ recognition and T2 accuracy, as did an indirect relationship between arousal ratings for $\mathrm{T} 1$ and $\mathrm{T} 2$ accuracy that was mediated by $\mathrm{T} 1$ recognition (see Figure 4).

\section{Capture Task}

Target identification. Figure 6 presents the mean color target accuracy (\% correct responses) for each pseudotarget type (neutral, negative, positive, sexual/taboo, and threatening) as a function of the lag between the pseudotarget and target (see Table 1 for ANOVA results). Again, sexual/taboo pseudotargets led to lower overall target accuracy $(M=79 \%$ $\pm 0.2 \%)$ than all other word types $\operatorname{did}(M \mathrm{~s}>84 \%, p \mathrm{~s}<$ $.04)$, which did not differ from each other (all $p \mathrm{~s}>.90$ ). 


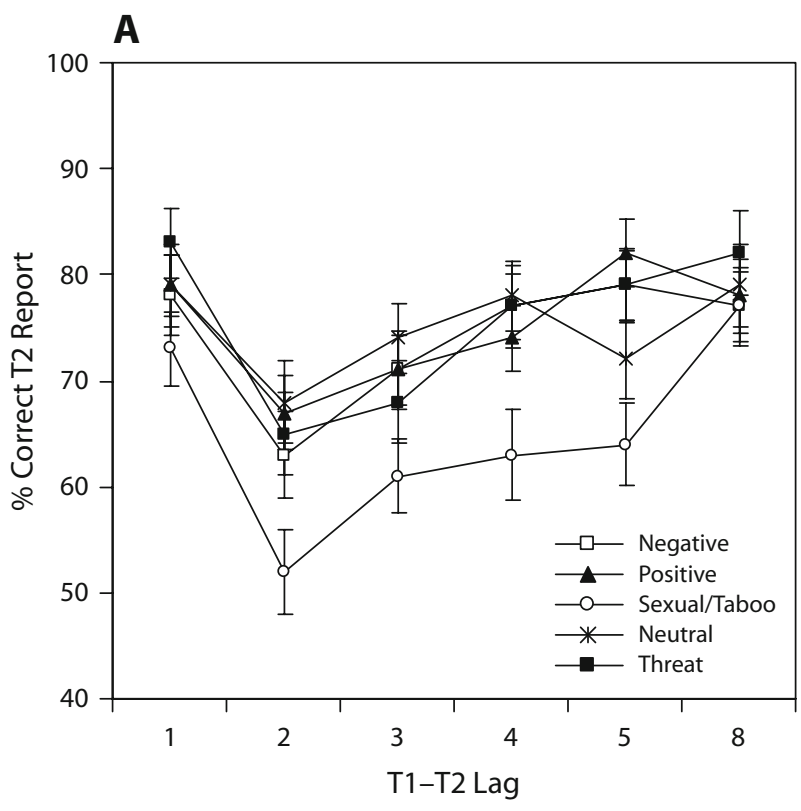

B

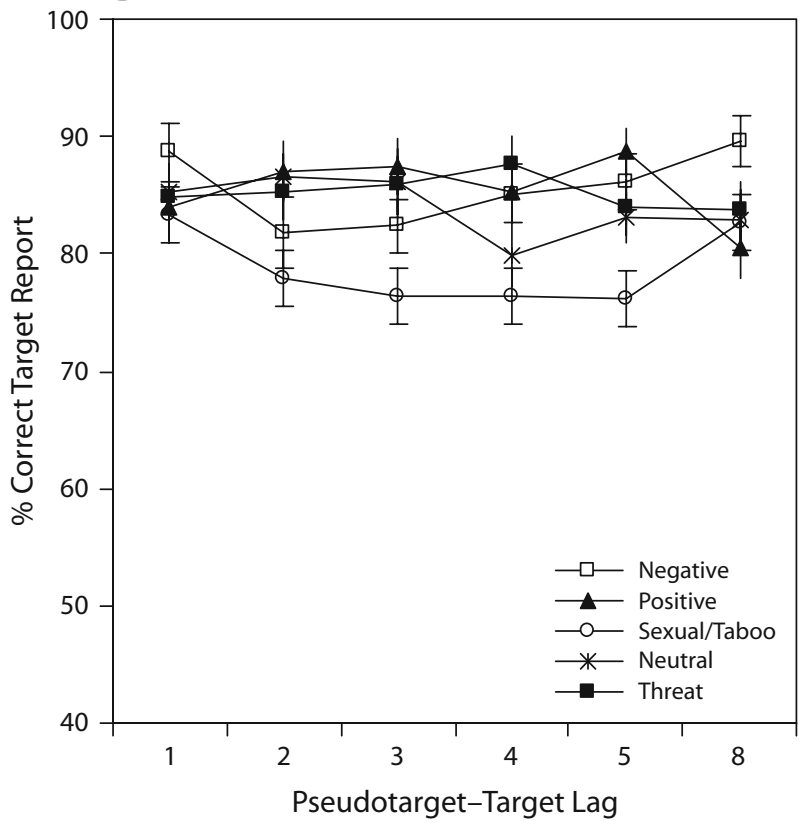

Figure 6. (A) The mean percentage of correct $\mathrm{T} 2$ responses as a function of $\mathrm{T} 1$ word type and the lag between $\mathrm{T} 1$ and $\mathrm{T} 2$ in the AB task, Experiment 2. Error bars represent the standard error for each mean. (B) The mean percentage of correct target responses as a function of pseudotarget word-type and the lag between pseudotarget and targets in the capture task, Experiment 2. Error bars represent the standard error for each mean.

Word ratings and target identification. Once again, higher arousal ratings were correlated with lower color target accuracy. Although valence, as before, did not predict target accuracy, valence extremity did (see Table 2). As in the capture task from Experiment 1, both arousal and valence extremity accounted for significant amounts of variance in target accuracy in a simultaneous regression analysis, but in opposite directions (see Table 3).
Recognition memory and target identification. The number of correct recognitions (hits) awarded to pseudotarget $(M=2.3$ for neutral words, 2.0 for negative words, 2.6 for positive words, 2.3 for threatening words, and 6.0 for sexual/taboo words) differed across word types $[F(4,235)=$ $28.75, p<.001]$. Sexual/taboo words were recognized significantly more often than other word types $(p s<.001)$, which did not differ from each other (all $p \mathrm{~s}>.90$ ).

The mean number of erroneously identified foils was 1.9 for neutral words, 1.8 for negative words, 2.5 for positive words, 1.8 for threat words, and 2.0 for sexual/taboo words, which did not differ across word types $[F(4,235)=$ $1.17, p>.50]$.

Corrected recognition scores (hits - false alarms) were 0.4 for neutral words, 0.2 for negative words, 0.1 for positive words, 0.5 for threat words, and 4.0 for sexual/taboo words, differing across word type $[F(4,235)=20.82, p<$ $.001]$. Sexual/taboo words were better recognized than other word types $(p s<.001)$, which did not differ from each other (all $p \mathrm{~s}>.90)$. Correlational analyses indicated that corrected recognition scores were positively related to arousal ratings (see Table 2). Valence extremity (but not valence) was negatively correlated with corrected recognition. As in Experiment 1, simultaneous regression revealed that higher arousal ratings were associated with better corrected recognition, whereas increased valence extremity was associated with poorer corrected recognition of the pseudotarget (see Table 4).

As in Experiment 1, better corrected recognition for pseudotarget predicted lower target accuracy (see Table 2), even when variability due to arousal was partialled out [partial $r=-21, t(237)=3.38, p=.001]$. Unlike in Experiment 1 , arousal ratings still predicted color target accuracy in the capture task when variance due to corrected recognition for pseudotarget was removed (see Table 5). These results provide support for a partially mediated model in which some, but not all, of the relationship between the pseudotarget's arousal rating and accuracy for a subsequent target can be accounted for by increased processing and subsequent recognition of the arousing distractor.

\section{Cross-Task Comparisons}

Correlational analyses revealed that in Experiment 2, words that were remembered in the $\mathrm{AB}$ task were also more likely to be remembered in the capture task $[r(238)=.53$, $p<.001]$. In addition, $\mathrm{T} 1$ words that produced $\mathrm{T} 2$ report failures in the $\mathrm{AB}$ task were likely to be the same words that impaired target accuracy when presented as distractors in the capture task $[r(238)=.38, p<.001]$.

\section{Discussion}

The results of Experiment 2 were consistent with those of Experiment 1 in that sexual/taboo words presented as T1s or to-be-ignored distractors led to reduced accuracy for subsequent neutral RSVP targets. As in Experiment 1, these sexual/taboo words were also better recognized than other words, and memory for these words mediated the relationship between arousal ratings of the emotional words and report accuracy for subsequent targets. These results suggest that sexual/taboo words are preferentially 
attended and encoded at the expense of subsequent neutral material in RSVP.

Experiment 2 was similar to Experiment 1, with a few exceptions. First, in Experiment 1, it was possible that participants checked taboo words most often simply because they were attention-getting words, not because they remembered seeing those words earlier in the experiment. To remove any potential response bias, the recognition test list was expanded in Experiment 2 to include an equal number of never-seen foils for each word type, and targets and foils were counterbalanced across participants. A less biased recognition score (hits minus foil errors) was calculated for each task in order to ensure that identification of T1s and distractors represented true recognition for words seen earlier during the task. Participants showed a slight tendency to falsely identify emotional material more often in the $\mathrm{AB}$ task; but for both tasks, the corrected recognition measure replicated the results of Experiment 1, showing that memory for the emotional words was greater than for sexual/taboo words. Furthermore, recognition of the emotion words negatively predicted accuracy on targets that followed them. Indeed, memory performance was found to fully (AB task) or partially (capture task) mediate the relationship between target accuracy and arousal ratings, just as in Experiment 1.

Second, to eliminate any possible confusion or carryover effects, Experiment 2 used a between-participants design where participants performed only the $\mathrm{AB}$ task or only the capture task. The high degree of similarity in the results from Experiment 1 and Experiment 2 suggest that the results of Experiment 1 were not due to confusion over performing two RSVP tasks and completing two separate recognition test lists. Even though there were two separate groups of participants performing the $\mathrm{AB}$ and capture tasks in Experiment 2, we again found that the emotion words that were better recognized and led to reduced accuracy for subsequent targets in the $\mathrm{AB}$ task tended to be the same words that were better recognized and led to reduced accuracy for subsequent targets in the capture task.

Finally, because threatening words might be as arousing as taboo words - although due to fear instead of titillation or shock - a new list of physically threatening words was introduced to distinguish fear-inducing, threatening words from sexually oriented, taboo words. For both tasks, the results clearly showed that memory was increased for sexual/ taboo words, but not for threatening words, and, whereas sexual/taboo words led to reduced accuracy for subsequent RSVP targets, threatening words did not. Thus, although sexual/taboo words appear to receive preferential attentional processing in RSVP, threatening words do not appear to differ from neutral, positive, or sadness-related words.

\section{GENERAL DISCUSSION}

Overall, there were five goals for the present study. The first was to examine whether the emotional content of the T1 word would modulate the magnitude of the $\mathrm{AB}-\mathrm{a}$ finding that has not yet been reported. In both experiments, a larger $\mathrm{AB}$ was observed with sexual/taboo T1 words than with neutral, threatening, positive, or negative $\mathrm{T} 1$ words, which did not produce differences in the size of the $\mathrm{AB}$. The second goal was to replicate the finding that sexual/taboo words that were presented as to-be-ignored distractors in RSVP would reduce report accuracy for targets that were presented shortly afterward - an involuntary attentional blink. This finding was replicated in both experiments. Sexual/ taboo words set off an involuntary AB, but other word types did not. The third goal was to examine whether the words that reduced $\mathrm{T} 2$ accuracy when presented as $\mathrm{T} 1$ in the $\mathrm{AB}$ paradigm were the same words that reduced target accuracy when presented as to-be-ignored distractors in the capture paradigm. A high degree of similarity in the words was found when the same participants performed both RSVP paradigms (Experiment 1) and when different participants performed the two paradigms (Experiment 2), suggesting that the same mechanism may underlie both effects. The fourth goal was to examine whether a word's arousal rating, valence rating, or valence extremity rating could explain why that word would be more effective than others at capturing attention at the expense of subsequent targets in RSVP. In both experiments, high arousal ratings were associated with poor accuracy to subsequent targets, but high valence and valence extremity ratings were not; indeed, valence extremity was positively associated with target accuracy once arousal was accounted for. The final goal was to ascertain a possible mechanism for the above effects by examining the degree to which the emotion words were recognized in a surprise recognition memory test. In both experiments, sexual/ taboo words were recognized more frequently than other words, and better recognition of an emotion word was associated with lower accuracy for subsequent targets. We also observed that memory performance mediated the relationship between arousal ratings and target accuracy, providing a possible mechanism for the present pattern of results.

\section{Attentional Allocation \\ to Emotionally Arousing Stimuli}

Sexual/taboo words had a greater detrimental effect on report of subsequent targets than other types of emotion words or neutral words did, both when presented as $\mathrm{T} 1 \mathrm{~s}$ in the $\mathrm{AB}$ task and as to-be-ignored distractors in the capture task. These results are consistent with those from other paradigms, such as digit parity, inattention blindness, Stroop, and dot probe, in which emotionally arousing stimuli have been shown to receive preferential attention (e.g., Aquino \& Arnell, 2007; Mack \& Rock, 1998; MacKay et al., 2004; Mogg et al., 1997). As in these other attention paradigms, a benefit of the RSVP task is that any differences in accuracy for subsequent targets across the emotion conditions suggest that emotional arousal exerted its effect online, during the RSVP task (i.e., at the time of first target appearance), preceding any effects of longer term memorial consolidation of sexual/taboo words (see, e.g., Sharot \& Phelps, 2004).

The present findings are also consistent with other studies investigating attention to emotional material in RSVP. Anderson (2005), Anderson and Phelps (2001), and Keil and Ihssen (2004) all observed a reduced AB when arousing words were presented as T2s in RSVP, suggesting that arousing words were able to overcome the attentional defi- 
cit that underlies the AB. In addition, Arnell et al. (2007) showed that sexual/taboo words set off an $A B$ when presented as to-be-ignored distractors, but that threatening, positive, sadness-related, and neutral words did not. Similarly, Most et al. (2007) and Most, Chun, et al. (2005) showed that gory, disgusting pictures and erotic sexual pictures were both able to create an involuntary $\mathrm{AB}$ when presented as to-be-ignored distractors prior to single targets. Therefore, it appears that emotionally arousing stimuli receive preferential attentional processing in RSVP, whether they are presented as T1, T2, or to-be-ignored distractors.

Anderson (2005) presented two alternative explanations for the reduced AB with sexual/taboo T2s. He reasoned that sexual/taboo T2 words either had a lower threshold for activation that freed them from the attentional limitations that underlie the $\mathrm{AB}$ or attracted more attentional resources than other, less emotionally arousing words. Anderson showed that the enhanced report of sexual/ taboo $\mathrm{T} 2 \mathrm{~s}$ during the $\mathrm{AB}$ interval was independent of $\mathrm{T} 1$ accuracy and response latency, suggesting that sexual/ taboo $\mathrm{T} 2$ words did not attract attention away from $\mathrm{T} 1$ processing, but instead required less attention to be reported successfully. This contrasts with previous studies showing that accuracy for emotionally neutral T2s decreases with increasing T1 latency (see Jolicœur, 1999).

Anderson (2005) may be correct in stating that processing of sexual/taboo words in RSVP requires less attention, but our results suggest that, at least in certain circumstances, sexual/taboo RSVP words actually receive more attentional processing, leading to reduced accuracy for trailing targets. One way to account for the apparent divergence between our interpretation and Anderson's interpretation is to examine two types of attentional processing (earlier attentional orienting and later sustained attention) in the AB. Data from multiple studies support the notion that both orienting and sustained attention are involved in the appraisal of novel stimuli (see, e.g., Most, Scholl, et al., 2005; Scherer, 2001; Scherer, Dan, \& Flykt, 2006; Schimmack, 2005). By itself, transient orienting to a novel stimulus produces a representation that is too fragmentary to form the basis of a conscious perception. For a visual stimulus to enter conscious awareness, a reiterative process of interpretation and reinterpretation of the stimulus (i.e., sustained attention; Most, Scholl, et al., 2005) or an initial relevance check followed by multiple appraisals (Scherer, 2001 ) is necessary. However, the initial orienting is important because the preconscious information gleaned from this stage determines how much sustained attention will be subsequently allocated to the stimulus (see, e.g., Morris, Öhman, \& Dolan, 1998; Whalen, Bush, et al., 1998).

Suppose that sexual/taboo words generate both increased attentional orienting (during Stage 1 processing) and increased sustained attention (during Stage 2 processing), as compared with other words. If this were indeed true, changing the temporal position of the sexual/taboo word in RSVP could highlight different attentional effects of such words because it would alter the temporal location at which attentional resources are concentrated. When sexual/taboo words are presented as T1s, both Stage 1 attentional orienting and Stage 2 sustained attention to these words may be enhanced more than neutral T1s. While increased Stage 1 attentional orienting to a sexual/taboo T1 is unlikely to have consequences for an upcoming neutral target, increased Stage 2 sustained attention to such a T1 could impair the processing of the $\mathrm{T} 2$ by appropriating a greater share of available attentional resources, resulting in greater blinking of the emotionally neutral $\mathrm{T} 2$. This is consistent with the idea that $\mathrm{AB}$ duration reflects the amount of processing allotted to a verbal T1 (Hommel \& Doeller, 2005; Olson, Chun, \& Anderson, 1991), and with resource sharing accounts of the AB (e.g., Shapiro, Schmitz, Martens, Hommel, \& Schnitzler, 2006). Similarly, Stage 1 attentional orienting is likely to be faster and more intense for a sexual/taboo T2 word than for a neutral T2. When the strength of its Stage 1 attentional orienting is increased, sexual/taboo T2's representation may be able to survive the postponement of its own Stage 2 processing until T1's processing is completed. Therefore, the $\mathrm{AB}$ may be larger when emotionally arousing words are presented as distractors or T1s, due to prolonged Stage 2 attention allotted to these distractors or $\mathrm{T} 1 \mathrm{~s}$, but it can be smaller when the same words are presented as T2s, due to enhanced Stage 1 orienting to $\mathrm{T} 2 \mathrm{~s}$ that allows $\mathrm{T} 2$ representations to survive the normal wait, while $\mathrm{T} 1$ processing is completed.

Proposing enhanced Stage 1 attentional orienting for sexual/taboo words is consistent with well-known physiological evidence on the role of the amygdala in mediating arousal (e.g., Cahill \& McGaugh, 1998; Kensinger \& Corkin, 2004; LaBar \& Phelps, 1998; LeDoux, 2000) and with evidence showing that amygdalar coding of emotional stimuli modulates sensory cortex and top-down, frontoparietal attentional circuits, resulting in perceptual enhancement of these stimuli (Vuilleumier, 2005). Thus, because of amygdalar activity and the allocation of additional processing resources, perceptual representations of emotionally arousing or sexual/taboo words may indeed "burn brighter and longer" (Anderson, 2005, p. 271) than surrounding neutral words. Kensinger and Corkin (2004) have shown that emotionally arousing words can influence perceptual processing even under divided attention conditions, suggesting that the perception- and memoryenhancing activity of the amygdala is relatively automatic (see also Whalen, Ranch, et al., 1998). When sensory processing is enhanced, the stimulus is preferentially selected for early perceptual analysis, which also facilitates its Stage 2 identification and consolidation in working memory (Keil, Ihssen, \& Heim, 2006). Subsequent allocation of attention has been shown to improve the discriminability of attended stimuli and accelerate the rate at which they are processed (see, e.g., Canli et al., 2000; Carrasco \& McElree, 2001; Hamann, Ely, Grafton, \& Kilts, 1999).

Therefore, regardless of the position of the sexual/taboo word in the stream, its perceptual representation and salience should be enhanced automatically. When sexual/ taboo words are presented as T1s, this enhancement would be accompanied by an increase in sustained attention that would lead to a greater AB. However, when sexual/taboo words are presented as T2s, this enhancement would allow fragile Stage 1 representations to outlast T1 processing, resulting in an attenuated $\mathrm{AB}$. 


\section{Efficacy of Sexual/Taboo Words}

It has been suggested that even when attentional effects of emotionally arousing words may be found, they are very short-lived. In a digit parity judgment task, Harris and Pashler (2004) showed that the increased response times observed when digits were paired with threatening, incidental, emotional distractor words habituated after a single trial. However, in the present study, sexual/taboo words were presented 48 times, and each emotional word was presented twice in each paradigm of each experiment. Nonetheless, the detrimental effect of arousing words on subsequent target accuracy was significant in both paradigms in both experiments, and equal in magnitude for the paradigm done first and the paradigm done second in Experiment 1. Thus, the attentional system's preferential response to sexual/taboo words was maintained across a comparatively long period of time.

MacKay et al. (2004) have pointed out that repeating a taboo word produces two separate effects: habituation to the word itself and a more general attenuation in the surprise associated with encountering explicit, taboo words in a laboratory study. Since the unexpectedness of sexual/ taboo distractors should wear off with repeated presentations, the longevity of their effects may have less to do with the general surprise of seeing such words in a laboratory setting and more to do with the strongly arousing nature of the words themselves. Indeed, recent results from our laboratory suggest that the sexual/taboo words used in the present study are capable of capturing attention when presented as distractors across at least nine presentations of 12 different words, even when participants were shown all of the pseudotarget distractors in advance and instructed to ignore them (Arnell et al., 2007). The discrepancy between the apparent ability of sexual/taboo words to attract/maintain attentional resources over several hundred trials (Aquino \& Arnell, 2007; Arnell et al., 2007; MacKay et al., 2004) and the relative inability of other high-priority words to attract/maintain attention (Aquino \& Arnell, 2007; Arnell et al., 2007; Harris et al., 2004) may be partly explained by the fact that sexual/taboo words generate heightened emotional arousal, whereas words that may be salient because they are important or negative (but not particularly arousing) do this to a much lesser degree.

\section{Arousal and Valence Extremity}

In both experiments, we observed that $\mathrm{T} 2$ accuracy was negatively correlated with arousal ratings but positively correlated with valence extremity values for emotional words, once variance attributable to arousal was accounted for. Thus, arousal ratings and valence extremity with arousal partialled out were related to T2 report in opposite directions. Finding that high valence extremity improved $\mathrm{T} 2$ accuracy was unanticipated. To account for these relationships, we suggest the following: Correlations between arousal and valence extremity were high in all emotion conditions but sexual/taboo. Therefore, when arousal was partialled from valence extremity, much of the variability due to valence extremity was removed from all conditions other than sexual/taboo. In the sexual/taboo condition, many of the sexual/taboo words were high in arousal but low to moderate in valence extremity, including the words found to be most effective at reducing accuracy for subsequent targets (e.g., penis, orgy). Thus, titillating sexual words were highly arousing and more effective than other words at capturing attention, yet they happened to have low valence extremity scores; both of these facts were reflected in the analyses.

In contrast with sexual/taboo words, however, highly valenced words-positive, negative, and threatening words - were poorly recognized on the surprise memory test. Thus, words with higher valence extremity ratings did not show reduced accuracy for subsequent targets generally and were not preferentially encoded into memory. Only the sexual/taboo words were effective at reducing target accuracy at all. When data from the various emotion conditions were examined separately, the sexual/ taboo condition showed significant relationships between T2 accuracy and arousal and valence extremity as above, but this was not true for negative, positive, neutral, or threat conditions in which no relationships were observed. Therefore, outside of the sexual/taboo condition, valence extremity and arousal did not influence target accuracy. This is likely because there was little variability in target accuracy in the other conditions, and, as such, there was no meaningful variability to predict. It does not appear that the absence of these relationships was due to the high intercorrelations between arousal and valence extremity that existed in all conditions except for sexual/taboo. For the positive, negative, threat, and neutral conditions, target accuracy was not predicted by arousal or valence extremity, even in the zero-order correlations in which the interrelationship between arousal and valence extremity was irrelevant.

Why might emotional arousal show meaningful relationships with accuracy for subsequent targets and recognition memory, whereas valence and valence extremity do not? First, converging evidence suggests that the two main dimensions of emotional stimuli (arousal and valence) may be supported by different neural networks. Kensinger and Corkin (2004) have shown that distinct neural routes may serve as substrates for the emotionally arousing aspects of words versus their emotional valence. In Kensinger and Corkin's study, arousing words elicited greater activation in an amygdalar-hippocampal circuit, whereas negative words elicited greater activation in a prefrontal cortexhippocampal circuit associated with controlled processes. Similarly, Dillon, Cooper, Grent-'t-Jong, Woldorff, and LaBar (2006) reported a topographical dissociation at the scalp between ERP indices of arousal and semantic cohesion. In support of these views, Maljkovic and Martini (2005) have described independent effects of arousal and valence in terms of the rates at which visual information from photographs accumulates in short term memory.

Second, sexual/taboo words appear to strongly manipulate arousal, providing perhaps the greatest potential to capture and hold attention. By invoking an initial reaction of shock, embarrassment, or heightened interest, these words are highly likely to invoke heightened reiterative perceptual processing and amygdalar-hippocampal 
binding responses (Anderson, 2005; Anderson \& Phelps, 2001; Kensinger \& Corkin, 2004; MacKay et al., 2004). The present pattern of results suggests the influence of arousal and activation of the amygdalar-hippocampal circuit in response to sexual/taboo words during RSVP target search.

\section{A Proposed Mechanism for Poor Report of Secondary Targets}

Sexual/taboo words were more likely than other words to disrupt T2 report. In two experiments, the negative relationship between arousal ratings and target report accuracy was accounted for by recognition performance in both the AB and capture paradigms. We posit that enhanced Stage 2 attentional processes supporting consolidation of first targets underlie the improved memory performance. The enhanced attention could be engaged via the modulation of additional brain regions (e.g., parietal) by the amygdalar-hippocampal circuit, as suggested by Vuilleumier (2005). It appears that the presence of sexual/ taboo words did not merely shock the system, but may have triggered the attentional processes conducive to better Stage 2 consolidation, ultimately leading to better recognition of these words. This interpretation is consistent with the results and model of MacKay et al. (2004). Using taboo words in Stroop and other tasks, MacKay et al. demonstrated that the activation of highly arousing meanings facilitated attention to the taboo words and the binding of meaning to other contextual features of the words, such as font, color, or location. To explain this effect, MacKay et al. posited that these words produced emotional reactions that engaged the amygdala, which in turn influenced the hippocampus to bind the arousing stimuli to their context. Facilitated binding of taboo words led to superior memory for the words and their attributes. Thus, the results from the surprise recognition task used here are consistent with these findings.

Although the data are correlational, and more than one pattern of paths could explain the interrelationship among target accuracy, arousal ratings, and recognition performance, the present model provides a plausible mechanism to explain the ability of sexual/taboo words to disrupt second-target accuracy in RSVP. Arousal ratings did predict memory performance and accuracy for subsequent targets, but it is also worth noting that, sometimes, words with similar arousal ratings had quite different recognition and/or target accuracy scores. Thus, there is likely more to the character of the words that led to particular capture effects than just arousal. In Experiment 2, we observed that sexual/taboo words produced stronger effects than threat words, but why some sexual/taboo words were more effective than others is not presently known. It was not simply the case that the most vulgar of the sexual/taboo words were the most effective. Indeed, some of the sexual/taboo words that were most successful at disrupting $\mathrm{T} 2$ report (e.g., orgasm, penis) were not vulgar.

\section{Processing of T1}

It is clear that the font decision in the $A B$ task could have been completed efficiently based on perceptual in- formation alone, without necessarily reading any of the $\mathrm{T} 1$ words. If participants tried to inhibit reading and concentrate on the T1 fonts, then sexual/taboo T1s apparently derailed this strategy, because their meanings were encoded and remembered. If more attention had been devoted to sexual/taboo T1s, and this facilitated greater binding of T1 features and superior memory for T1 words, as suggested by MacKay et al. (2004), then one might have expected font accuracy to increase more for sexual/taboo T1s than for other emotion categories. Alternatively, one could conceptualize the T1 font task as being an attentional dilemma similar to that of a Stroop task, in which participants inhibited focusing on the semantics of the word while attending to whether T1 words were presented in capitals or small letters. If there were greater interference for sexual/taboo words during the T1 task, one might have expected font-decision accuracy to suffer when the meanings of sexual/taboo T1s were attended to. Neither increased T1 accuracy nor decreased T1 accuracy was observed for sexual/taboo T1s; T1 accuracy did not differ across the emotion word categories.

Given the high T1 accuracy rate, it is possible that a ceiling effect simply obscured any differences in T1 accuracy across the emotion conditions. It is also possible that sexual/taboo T1s did interfere with the T1 font task, but that this interference simply resulted in longer, not less accurate, processing of $\mathrm{T} 1-\mathrm{a}$ finding that could not be observed given the unspeeded nature of the T1 task. Jolicœur (1999) has shown that when T1 requires an online, speeded response, the $\mathrm{AB}$ is larger on trials where the $\mathrm{T} 1$ response is slower than on trials where the $\mathrm{T} 1 \mathrm{re}-$ sponse is faster, even when $\mathrm{T} 1$ accuracy rates are similar. Therefore, it is possible that increased interference was observed between the semantic and font information for sexual/taboo T1s, but that the font decision was performed as accurately - just more slowly. In fact, any factor that increases processing time for T1s could lead to delays in their Stage 2 attentional consolidation; this would, in turn, impair Stage 2 consolidation of T2 (see, e.g., Chun \& Potter, 1995; Jolicœur, 1999).

If Stroop-like interference between the font and meaning of a sexual/taboo T1 were indeed responsible for impaired T2 consolidation, it might be possible to reduce the interference and the increased $\mathrm{AB}$ with sexual/taboo T1s by asking participants to report the identity of $\mathrm{T} 1$ (a task that would require the use of semantic processing, instead of making the orthogonal font decision). Understanding the potential for Stroop-like interference in the T1 task is important, because the enhanced $\mathrm{AB}$ with sexual/ taboo T1s could be due to greater interference during $\mathrm{T} 1$ processing, rather than greater Stage 2 attention, as we propose. An interference explanation seems less likely, though, given that similar results were found when sexual words were presented as to-be-ignored distractors, and these distractors required no orthogonal task. Also, memory was better for sexual/taboo words, which one might not expect if their word meanings were inhibited. Further research will be needed in order to decide between the Stroop explanation and the sustained attention explanation advanced here. 


\section{CONCLUSIONS}

When arousing sexual/taboo words were presented as $\mathrm{T} 1$, a larger $\mathrm{AB}$ was observed. These same words were also able to capture attention involuntarily, disrupting accuracy to subsequent targets, even when they were presented as to-be-ignored distractors. The relationship between the arousal value of the emotion word and subsequent target report accuracy was mediated by recognition performance for these first target words, suggesting that emotion words received preferential Stage 2 processing at the expense of subsequent targets. Superior memory for sexual/taboo words and reduced accuracy for targets that follow them may depend on the automatic activation of the amygdalarhippocampal circuit.

\section{AUTHOR NOTE}

This work was made possible through grants to the second author from the Natural Sciences and Engineering Research Council (NSERC), the Canadian Foundation for Innovation (CFI), and the Ontario Innovation Trust (OIT), and through an NSERC student fellowship to the first author. We thank Kirk Stokes and Jamie Faragelli for assistance with data collection. Portions of this study were presented at the 45th Annual Meeting of the Psychonomic Society in Minneapolis, MN. Correspondence concerning this article should be sent to K. M. Arnell, Department of Psychology, Brock University, St. Catharines, ON, Canada L2S 3A1 (e-mail: karnell@brocku.ca).

\section{REFERENCES}

Anderson, A. K. (2005). Affective influences on the attentional dynamics supporting awareness. Journal of Experimental Psychology: General, 134, 258-281.

Anderson, A. K., \& Phelps, E. A. (2001). Lesions of the human amygdala impair enhanced perception of emotionally salient events. $\mathrm{Na}$ ture, 411, 305-309.

Aquino, J. M., \& Arnell, K. M. (2007). Attention and the processing of emotional words: Dissociating effects of arousal. Psychonomic Bulletin \& Review, 14, 430-435.

Arnell, K. M., Killman, K. V., \& FiJavz, D. (2007). Blinded by emotion: Target misses follow attention capture by arousing distractors in RSVP. Emotion, 7, 465-477.

Barnard, P. J., Ramponi, C., Battye, G., \& Mackintosh, B. (2005). Anxiety and the deployment of visual attention over time. Visual Cognition, 12, 181-211.

Barnard, P. J., Scott, S., Taylor, J., May, J., \& Knightley, W. (2004). Paying attention to meaning. Psychological Science, 15, 179-186.

Broadbent, D., \& Broadbent, M. (1987). Anxiety and attentional bias: State and trait. Cognition \& Emotion, 2, 165-183.

Cahill, L., \& McGaugh, J. L. (1995). A novel demonstration of enhanced memory associated with emotional arousal. Consciousness \& Cognition, 4, 410-421.

Cahill, L., \& McGaugh, J. L. (1998). Mechanisms of emotional arousal and lasting declarative memory. Trends in Neurosciences, 21, 294-299.

Canli, T., Zhao, Z., Brewer, J., Gabrieli, J. D. E., \& Cahill, L. (2000). Event-related activation in the human amygdala associates with later memory for individual emotional experience. Journal of Neuroscience, 20, RC99-RC103.

Carrasco, M., \& McElree, B. (2001). Covert attention accelerates the rate of visual information processing. Proceedings of the National Academy of Sciences, 98, 5363-5367.

Chun, M. M., \& Potter, M. C. (1995). A two-stage model for multiple target detection in rapid serial visual presentation. Journal of Experimental Psychology: Human Perception \& Performance, 21, 109-127.

Compton, R. J., Banich, M. T., Mohanty, A., Milham, M. P., HerRington, J., Miller, G. A., ET AL. (2003). Paying attention to emotion: An fMRI investigation of cognitive and emotional Stroop tasks. Cognitive, Affective, \& Behavioral Neuroscience, 3, 81-96.
Dijksterhuis, A., \& Aarts, H. (2003). On wildebeests and humans: The preferential detection of negative stimuli. Psychological Science, 14, 14-18.

Dillon, D. G., Cooper, J. J., Grent-'T-Jong, T., WoldorfF, M. G., \& LABAR, K. S. (2006). Dissociation of event-related potentials indexing arousal and semantic cohesion during emotional word encoding. Brain \& Cognition, 62, 43-57.

Gotlib, I. H., \& McCann, C. D. (1984). Construct accessibility and depression: An examination of cognitive and affective factors. Journal of Personality \& Social Psychology, 47, 427-439.

Hamann, S. [B.] (2001). Cognitive and neural mechanisms of emotional memory. Trends in Cognitive Sciences, 5, 394-400.

Hamann, S. B., Ely, T. D., Grafton, S. T., \& Kilts, C. D. (1999). Amygdala activity related to enhanced memory for pleasant and aversive stimuli. Nature Neuroscience, 2, 289-293.

Harris, C. R., \& PAshler, H. [E.] (2004). Attention and the processing of emotional words and names: Not so special after all. Psychological Science, 15, 171-178.

Harris, C. R., PAShler, H. E., \& Coburn, N. (2004). Moray revisited: High-priority affective stimuli and visual search. Quarterly Journal of Experimental Psychology, 57A, 1-31.

Hommel, B., \& Doeller, C. F. (2005). Selection and consolidation of objects and actions. Psychological Research, 69, 157-166.

Ito, T. A., Larsen, J. T., Smith, N. K., \& CaCioppo, J. T. (1998). Negative information weighs more heavily on the brain: The negativity bias in evaluative categorizations. Journal of Personality \& Social Psychology, 75, 887-900.

JoLICGUR, P. (1999). Dual-task interference and visual encoding. Journal of Experimental Psychology: Human Perception \& Performance, 25, 596-616.

KeIL, A., \& IHSSEN, N. (2004). Identification facilitation for emotionally arousing verbs during the attentional blink. Emotion, 4, 23-35.

KeIL, A., InsSEN, N., \& HeIM, S. (2006). Early cortical facilitation for emotionally arousing targets during the attentional blink. BMC Biology, 4, 23 .

Kensinger, E. A., \& Corkin, S. (2004). Two routes to emotional memory: Distinct neural processes for valence and arousal. Proceedings of the National Academy of Sciences, 101, 3310-3315.

KuČERA, H., \& Francis, W. N. (1967). Computational analysis of present-day American English. Providence, RI: Brown University Press.

LaBAR, K. S., \& CABEZA, R. (2006). Cognitive neuroscience of emotional memory. Nature Reviews Neuroscience, 7, 54-64.

LABAR, K. S., \& Phelps, E. A. (1998). Arousal-mediated memory consolidation: Role of the medial temporal lobe in humans. Psychological Science, 9, 490-493.

LANG, P. J. (1995). The emotion probe: Studies of motivation and attention. American Psychologist, 50, 372-385.

Lang, P. J., Greenwald, M. K., Bradley, M. M., \& Hamm, A. O. (1993). Looking at pictures: Affective, facial, visceral and behavioral reactions. Psychophysiology, 30, 261-273.

LeDoux, J. E. (2000). Emotion circuits in the brain. Annual Review of Neuroscience, 23, 155-184.

Luck, S. J., Vogel, E. K., \& Shapiro, K. L. (1996). Word meanings can be accessed but not reported during the attentional blink. Nature, 383, 616-618.

MACK, A., \& Rock, I. (1998). Inattentional blindness. Cambridge, MA: MIT Press.

MacKay, D. G., Shafto, M., Taylor, J. K., Marian, D. E., Abrams, L., \& DYER, J. R. (2004). Relations between emotion, memory and attention: Evidence from taboo Stroop, lexical decision and immediate memory tasks. Memory \& Cognition, 32, 474-488.

MacLeod, C., Mathews, A., \& TAta, P. (1986). Attentional bias in emotional disorders. Journal of Abnormal Psychology, 95, 15-20.

Maki, W. S., Frigen, K., \& PaUlson, K. (1997). Associative priming by targets and distractors during rapid serial visual presentation: Does word meaning survive the attentional blink? Journal of Experimental Psychology: Human Perception \& Performance, 23, 1014-1034.

Maljkovic, V., \& Martini, P. (2005). Short-term memory for scenes with affective content. Journal of Vision, 5, 215-229.

Mehrabian, A. (1991). Outline of a general emotion-based theory of temperament. In J. Strelau \& A. Angleitner (Eds.), Explorations in temperament: International perspectives on theory and measurement (pp. 75-86). New York: Plenum. 
Mehrabian, A. (1997). Comparison of the PAD and PANAS as models for describing emotions and for differentiating anxiety from depression. Journal of Psychopathology \& Behavioral Assessment, 19, 331-357.

Mogg, K., Bradley, B. P., De Bono, J., \& Painter, M. (1997). Time course of attentional bias for threat information in non-clinical anxiety. Behaviour Research \& Therapy, 35, 297-303.

Morris, J. S., Öhman, A., \& Dolan, R. J. (1998). Conscious and unconscious emotional learning in the human amygdala. Nature, 393, 467-470.

Most, S. B., Chun, M. M., Widders, D. M., \& Zald, D. H. (2005). Attentional rubbernecking: Cognitive control and personality in emotioninduced blindness. Psychonomic Bulletin \& Review, 12, 654-661.

Most, S. B., Scholl, B. J., Clifford, E. R., \& Simons, D. J. (2005). What you see is what you set: Sustained inattentional blindness and the capture of awareness. Psychological Review, 112, 217-242.

Most, S. B., Smith, S. D., Cooter, A. B., Levy, B. N., \& Zald, D. H. (2007). The naked truth: Positive, arousing distractors impair rapid target perception. Cognition \& Emotion, 21, 964-981.

Olson, I. R., Chun, M. M., \& Anderson, A. K. (2001). Effects of phonological length on the attentional blink for words. Journal of Experimental Psychology: Human Perception \& Performance, 27, 1116-1123.

Pratto, F., \& John, O. P. (1991). Automatic vigilance: The attentiongrabbing power of negative social information. Journal of Personality \& Social Psychology, 61, 380-391.

Raymond, J. E., Shapiro, K. L., \& Arnell, K. M. (1992). Temporary suppression of visual processing in an RSVP task: An attentional blink? Journal of Experimental Psychology: Human Perception \& Performance, 18, 849-860.

Russell, J. A. (1980). A circumplex model of affect. Journal of Personality \& Social Psychology, 39, 1161-1178.

SCHERER, K. R. (2001). Appraisal considered as a process of multilevel sequential checking. In K. R. Scherer, A. Schorr, \& T. Johnstone (Eds.), Appraisal processes in emotion: Theory, methods, research (pp. 92-120). Oxford: Oxford University Press.

SCHERER, K. R., DAN, E. S., \& FLYKT, A. (2006). What determines a feeling's position in affective space? A case for appraisal. Cognition \& Emotion, 20, 92-113.

Schimmack, U. (2005). Attentional interference effects of emotional pictures: Threat, negativity, or arousal? Emotion, 5, 55-66.

Schneider, W., Eschman, A., \& Zuccolotto, A. (2002). E-Prime user's guide. Pittsburgh, PA: Psychology Software Tools, Inc.

Shapiro, K. [L.], Driver, J., Ward, R., \& Sorensen, R. E. (1997). Priming from the attentional blink: A failure to extract visual tokens but not visual types. Psychological Science, 8, 95-100.

Shapiro, K. [L.], Schmitz, F., Martens, S., Hommel, B., \& SchnitzLER, A. (2006). Resource sharing in the attentional blink. NeuroReport, 17, 163-166.
Sharot, T., \& Phelps, E. A. (2004). How arousal modulates memory: Disentangling the effects of attention and retention. Cognitive, Affective, \& Behavioral Neuroscience, 4, 294-306.

Stormark, K. M., Nordby, H., \& Hugdahl, K. (1995). Attentional shifts to emotionally charged cues: Behavioural and ERP data. Cognition \& Emotion, 9, 507-523.

Vuilleumier, P. (2005). How brains beware: Neural mechanisms of emotional attention. Trends in Cognitive Sciences, 9, 585-594.

Whalen, P. J., Bush, G., McNally, R. J., Wilhelm, S., McInerney, S. C., Jenike, M. A., \& Rauch, S. L. (1998). The emotional counting Stroop paradigm: A functional magnetic resonance imaging probe of the anterior cingulate affective division. Biological Psychiatry, 44, 1219-1228.

Whalen, P. J., Rauch, S. L., Etcoff, N. L., McInerney, S. C., Lee, M. B., \& JeniKe, M. A. (1998). Masked presentations of emotional facial expressions modulate amygdala activity without explicit knowledge. Journal of Neuroscience, 18, 411-418.

Williams, J. M. G., Mathews, A., \& MacLeod, C. (1996). The emotional Stroop task and psychopathology. Psychological Bulletin, 120, 3-24.

Zigmond, A. S., \& Snaith, R. P. (1983). The hospital anxiety and depression scale. Acta Psychiatrica Scandinavica, 67, 361-370.

\section{NOTES}

1. It should be noted that by Stage 2 consolidation of first or second targets in $A B$ tasks, we refer to the online attentional binding by which Stage 1 representations become bound together and encoded into working memory (see Chun \& Potter, 1995; Jolicœur, 1999). This differs from how the term consolidation is often used in the memory literature, where it refers to the slower, involuntary instantiation in long-term memory that takes place after encoding is complete.

2. For lack of a better term, this category that contains sexual words, curse words, and threat words has been labeled taboo in Experiment 1 and sexual/taboo in Experiment 2. Although not all words in this list are taboo, the more obvious label "arousing" was avoided for this category, given that it would be easily confused with the arousal ratings discussed in each of the experiments.

3. It should be noted that valid word frequency estimates for several of the taboo words were impossible to obtain. The frequency estimates used here for the taboo condition are based on those few taboo words that are likely to have valid estimates. However, word frequency is unlikely to account for the enhanced attentional processing that taboo words received. Valid word frequency counts were available for all words in the other three emotion conditions (neutral, positive, and negative) and varied widely within each condition. However, $\mathrm{AB}$ size and attentional capture effects did not vary with word frequency. 
APPENDIX A

T1 and Pseudotarget Words for Experiment 1

\begin{tabular}{|c|c|c|c|}
\hline Neutral & Negative & Positive & Taboo \\
\hline aisle & broken & beauty & AIDS \\
\hline binder & decay & birthday & ass \\
\hline blimp & decline & bouquet & bastard \\
\hline butter & dismay & champ & bitch \\
\hline card & dull & cheer & clitoris \\
\hline chat & faded & flower & cock \\
\hline chew & fail & friendly & dildo \\
\hline dazzle & feeble & fun & erotic \\
\hline desk & guilt & glad & fire \\
\hline fish & negative & good & fuck \\
\hline gel & poorly & happy & gun \\
\hline glove & punish & holiday & incest \\
\hline guzzle & sad & joyful & lesbians \\
\hline haggle & slave & leisure & murder \\
\hline jacket & slob & prize & naked \\
\hline justify & suffer & sky & naughty \\
\hline loop & tedious & smart & nipples \\
\hline note & thief & smile & orgasm \\
\hline planet & tired & sunny & orgy \\
\hline ruffled & unhappy & sweet & penis \\
\hline spare & useless & tender & piss \\
\hline staple & weary & treasure & rape \\
\hline wire & weep & vacation & sexual \\
\hline zipper & wounded & winner & shit \\
\hline
\end{tabular}

APPENDIX B

Distractor Words for Experiments 1 and 2

\begin{tabular}{llll}
\hline absent & chapel & input & repeat \\
academy & chart & Irish & shirt \\
cheek & jump & slim \\
barn & chin & kingdom & speaker \\
barrel & compare & lock & sponsor \\
bases & dawn & luxury & stable \\
beam & dealt & manage & tactics \\
behalf & discuss & Mars & tail \\
belt & disk & meal & tire \\
bend & drying & melody & torn \\
border & eight & movie & treat \\
boss & enable & network & utterly \\
bother & expert & pile & whisk \\
carbon & flew & plaster & zero \\
casual & folder & repair & \\
\hline
\end{tabular}


APPENDIX C

T1 and Pseudotarget Words for Experiment 2

\begin{tabular}{|c|c|c|c|c|}
\hline Neutral & Negative & Positive & Threat & Sexual/Taboo \\
\hline aisle & abandon & ace & afraid & anus \\
\hline article & bitter & agree & agony & arousal \\
\hline autumn & boring & amuse & anger & ass \\
\hline banana & broken & beauty & burned & bastard \\
\hline book & defeat & best & cancer & bitch \\
\hline branch & depressed & birthday & choke & blowjob \\
\hline butter & disappoint & bouquet & crash & boobs \\
\hline cable & dismay & champ & crisis & breast \\
\hline card & dud & charming & damned & climax \\
\hline centre & dump & cheer & danger & clitoris \\
\hline class & embarrass & comfort & death & cock \\
\hline clock & failure & cool & disease & condom \\
\hline computer & fat & delight & doom & dildo \\
\hline cover & feeble & enchant & dread & erotic \\
\hline detail & flunk & fortune & enemy & fetish \\
\hline envelope & glum & friendly & evil & fondle \\
\hline event & humiliate & fun & fatal & foreplay \\
\hline fact & idiot & gift & fear & fuck \\
\hline field & lament & glad & fire & gay \\
\hline fish & lonely & good & fright & horny \\
\hline gate & loser & grace & gun & incest \\
\hline gel & lost & happy & harsh & kinky \\
\hline glove & mistake & holiday & hate & kissing \\
\hline guzzle & mope & home & hell & lesbians \\
\hline invention & mourn & interest & horror & lewd \\
\hline jacket & nobody & joy & hostile & libido \\
\hline knowledge & pathetic & laugh & hurt & lust \\
\hline layer & pity & leisure & kill & masturbate \\
\hline league & plight & lucky & knife & naked \\
\hline link & poor & paradise & malice & naughty \\
\hline lunch & problem & peace & murder & nipples \\
\hline note & regret & please & panic & orgasm \\
\hline paper & reject & polite & poison & orgy \\
\hline patrol & sad & positive & rage & passion \\
\hline pencil & slave & prize & savage & penis \\
\hline planet & slob & sky & scare & piss \\
\hline potato & sob & smart & scream & pussy \\
\hline report & sorrow & smile & shock & scrotum \\
\hline ruffled & sorry & sparkle & shriek & seduce \\
\hline shop & stink & success & spiteful & sexual \\
\hline spare & stupid & sunny & stabbed & shit \\
\hline speak & ugly & sweet & terror & slut \\
\hline staple & unhappy & tender & thief & testicle \\
\hline towel & unpopular & treasure & threat & tits \\
\hline truck & useless & vacation & torture & vagina \\
\hline viola & victim & warmth & tragic & vibrator \\
\hline wire & weep & welcome & violent & virgin \\
\hline zipper & worry & winner & war & whore \\
\hline
\end{tabular}

(Manuscript received April 1, 2005;

revision accepted for publication May 23, 2007.) 